\title{
Quantifying Cardiac Sympathetic Denervation: First Studies of 18F-Fluorohydroxyphenethylguanidines in Cardiomyopathy Patients
}

David M. Raffel ( $\square$ raffel@umich.edu )

University of Michigan https://orcid.org/0000-0002-7188-9463

Thomas C. Crawford

University of Michigan

Yong-Woon Jung

University of Michigan

Robert A. Koeppe

University of Michigan

Guie Gu

University of Michigan

Jill Rothley

University of Michigan

Kirk A. Frey

University of Michigan

\section{Research Article}

Keywords: sympathetic nervous system, arrhythmia, sudden cardiac death

Posted Date: May 5th, 2021

DOl: https://doi.org/10.21203/rs.3.rs-459675/v1

License: (c) (i) This work is licensed under a Creative Commons Attribution 4.0 International License.

Read Full License

Version of Record: A version of this preprint was published at European Journal of Nuclear Medicine and Molecular Imaging on August 13th, 2021. See the published version at https://doi.org/10.1007/s00259021-05517-7. 


\section{Quantifying Cardiac Sympathetic Denervation: First Studies of ${ }^{18}$ F-Fluorohydroxyphenethylguanidines in Cardiomyopathy Patients}

Running Title: Quantifying Cardiac Denervation

David M. Raffel, $\mathrm{PhD}^{\mathrm{a}}$, Thomas C. Crawford, $\mathrm{MD}^{\mathrm{b}}$, Yong-Woon Jung, $\mathrm{PhD}^{\mathrm{a}}$, Robert A. Koeppe, $\mathrm{PhD}^{\mathrm{a}}$, Guie Gu, MS ${ }^{\mathrm{a}}$, Jill Rothley, $\mathrm{CNMT}^{\mathrm{a}}$, Kirk A. Frey, MD, PhD ${ }^{\mathrm{a}}$,

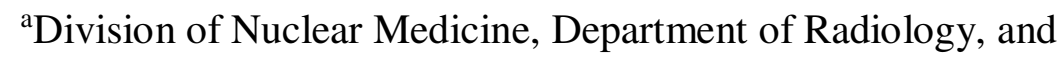

${ }^{b}$ Division of Cardiology, Department of Internal Medicine, University of Michigan Medical School, Ann Arbor, Michigan 48109

\section{Corresponding Author:}

David M. Raffel, Ph.D.

Division of Nuclear Medicine

Department of Radiology

2276 Medical Science I

1301 Catherine St.

Ann Arbor, MI 48109-5610

Telephone: (734) 936-0725

FAX: (734) 764-0288

Email: $\quad$ raffel@umich.edu

ORCID ID: 0000-0002-7188-9463 


\section{Abstract}

Purpose. The PET radiotracers $4-{ }^{18} \mathrm{~F}-$-fluoro- $m$-hydroxyphenethylguanidine $\left({ }^{18} \mathrm{~F}-4 \mathrm{~F}-\mathrm{MHPG}\right)$ and $3-{ }^{18} \mathrm{~F}$-fluoro- $p$-hydroxyphenethylguanidine $\left({ }^{18} \mathrm{~F}-3 \mathrm{~F}-\mathrm{PHPG}\right)$ were developed for quantifying regional cardiac sympathetic nerve density using tracer kinetic analysis methods. The aim of this study was to evaluate their performance in cardiomyopathy patients. Methods: Eight cardiomyopathy patients selected for surgical placement of an implantable cardioverter defibrillator (ICD) were scanned with ${ }^{18} \mathrm{~F}-4 \mathrm{~F}-\mathrm{MHPG}$ and ${ }^{18} \mathrm{~F}-3 \mathrm{~F}-\mathrm{PHPG}$ on different days. In addition, an ${ }^{13} \mathrm{~N}$-ammonia scan was performed to assess regional resting perfusion. The myocardial kinetics of ${ }^{18}$ F-4F-MHPG and ${ }^{18}$ F-3F-PHPG were analyzed using the Patlak graphical method to obtain Patlak slopes $K_{\mathrm{p}}(\mathrm{mL} / \mathrm{min} / \mathrm{g})$ as quantitative metrics of regional nerve density. Polar maps of the Patlak slopes were generated to map regional nerve density and to estimate the extent of cardiac denervation. For comparison purposes, regional tracer 'retention index' (RI) values (mL blood $/ \mathrm{min} / \mathrm{mL}$ tissue) were also calculated and used to estimate denervation extent metrics. Polar maps of resting perfusion estimates were used to estimate the pattern and extent of hypoperfusion. Results: Patlak analysis of ${ }^{18}$ F-4F-MHPG and ${ }^{18}$ F-3F-PHPG kinetics was successful in all subjects, demonstrating the robustness of this approach in cardiomyopathy patients. Substantial regional denervation was observed in all eight subjects, ranging from $25 \%$ to $74 \%$ of the left ventricle. Denervation zones were equal to or larger than the size of corresponding areas of hypoperfusion. Conclusion: ${ }^{18} \mathrm{~F}-4 \mathrm{~F}-\mathrm{MHPG}$ and ${ }^{18} \mathrm{~F}-3 \mathrm{~F}-\mathrm{PHPG}$ provide quantitative metrics of regional sympathetic nerve density and the extent of left ventricular denervation in patients with cardiomyopathy, supporting further clinical development of these agents.

Trial registration: Registered at the ClinicalTrials.gov website (NCT02669563).

URL: https://clinicaltrials.gov/ct2/show/NCT02669563 
Keywords: sympathetic nervous system, arrhythmia, sudden cardiac death 


\section{INTRODUCTION}

Sudden cardiac death (SCD), caused by a precipitous onset of cardiac arrhythmia, is responsible for $30 \%-50 \%$ of deaths in patients with cardiomyopathy [1]. Increasing use of implantable cardioverter defibrillators (ICDs) as preventative therapy against SCD has reduced mortality rates in this population [2]. The primary clinical measure used to select patients for ICD therapy is a left ventricular ejection fraction (LVEF) below 35\% [3]. Unfortunately, LVEF alone is a relatively poor predictor of who will benefit from ICD therapy, as only about 1 in 8 people who receive an ICD will experience a lifesaving shock [4]. Also, inappropriate shocks for arrhythmic events that are not life-threatening are not uncommon, and can be fatal [5]. Cardiologists recognize that new clinical metrics are needed for improved risk stratification of patients for ICD placement [6].

Remodeling of cardiac sympathetic innervation occurs in many diseases and has been linked to an increased risk of ventricular arrhythmias [7], the most frequent arrhythmia to cause SCD [8]. Myocardial infarction causes sympathetic denervation zones which are often larger than the corresponding myocardial scar, demonstrating the sensitivity of sympathetic neurons to ischemic insult [9]. Alterations in ion channel function in denervated myocardium can promote malignant ventricular arrhythmias [7]. Also, in denervated but viable zones around a scar, sympathetic nerve sprouting eventually occurs, leading to regional hyperinnervation [10]. The resulting heterogeneity in sympathetic innervation is thought to promote arrhythmogenic mechanisms that evolve into ventricular fibrillation $[11,12]$

The link between sympathetic remodeling and arrhythmogenesis has led to investigation of cardiac denervation metrics, obtained using sympathetic innervation radiotracers, as predictors of SCD risk. The multicenter ADMIRE-HF trial (AdreView Myocardial Imaging for Risk Evaluation

in Heart Failure) with ${ }^{123}$ I-meta-iodobenzylguanidine $\left({ }^{123} \mathrm{I}-\mathrm{mIBG}\right)$ established the independent power of the heart-to-mediastinum ratio (H/M ratio) measured with planar scintigraphy, a global 
measure of sympathetic denervation, to predict SCD risk [13]. The PAREPET trial (Prediction of Arrhythmic Events with Positron Emission Tomography) showed that the extent of regional cardiac denervation, measured with ${ }^{11} \mathrm{C}-(-)$ - $m$-hydroxyephedrine $\left({ }^{11} \mathrm{C}-\mathrm{HED}\right)$ and PET, could be used to classify ischemic cardiomyopathy patients into tertiles with low, medium and high risk of SCD [14]. These findings point to a potential role of cardiac neuroimaging in improved staging of patients for ICD therapy.

We recently developed two new cardiac sympathetic innervation radiotracers, $4-{ }^{18} \mathrm{~F}-$ fluoro- $m$ hydroxphenethylguanidine $\left({ }^{18} \mathrm{~F}-4 \mathrm{~F}-\mathrm{MHPG}\right)$ and $3-{ }^{18} \mathrm{~F}$-fluoro- $p$-hydroxphenethylguanidine $\left({ }^{18} \mathrm{~F}\right.$ 3F-PHPG). One advantage of these tracers is their fluorine-18 radiolabel, which permits distribution to PET centers without radiochemistry facilities. However, our main motivation was to develop tracers with improved kinetics for more accurate quantification of regional nerve density using tracer kinetic analysis techniques. ${ }^{18} \mathrm{~F}-4 \mathrm{~F}-\mathrm{MHPG}$ and ${ }^{18} \mathrm{~F}-3 \mathrm{~F}-\mathrm{PHPG}$ have slower neuronal uptake rates than ${ }^{123} \mathrm{I}-\mathrm{mIBG}$ and ${ }^{11} \mathrm{C}-\mathrm{HED}$ and much longer neuronal retention times (i.e., they have 'irreversible' tissue kinetics) [15]. Slowing neuronal uptake rates reduces the flowlimitation effects that occur for tracers with rapid uptake into tissue compartments, which in principle should greatly improve sensitivity for detecting early denervation [16]. Irreversible tissue kinetics affords high tissue concentrations of the tracers for imaging despite the slower neuronal uptake rates, and allows for the application of alternative kinetic analysis techniques. Specifically, pilot studies with ${ }^{18} \mathrm{~F}-4 \mathrm{~F}-\mathrm{MHPG}$ and ${ }^{18} \mathrm{~F}-3 \mathrm{~F}-\mathrm{PHPG}$ in non-human primates and healthy human subjects have shown that the Patlak graphical method [17], used for tracers with irreversible tissue kinetics, provides reproducible metrics of regional sympathetic nerve density [15, 18]. The goal of this study was to perform a head-to-head comparison of ${ }^{18} \mathrm{~F}-4 \mathrm{~F}-\mathrm{MHPG}$ and ${ }^{18} \mathrm{~F}-3 \mathrm{~F}-\mathrm{PHPG}$ in cardiomyopathy patients selected for ICD placement to determine which one has the best overall 
imaging and kinetic properties for quantitative assessments of cardiac sympathetic denervation. These studies are a requisite step before performing a larger scale clinical trial designed to determine the power of one of these new innervation tracers to predict SCD risk in patients being evaluated for ICD therapy.

\section{METHODS}

Study Design. Subjects were scanned with both ${ }^{18}$ F-4F-MHPG and ${ }^{18}$ F-3F-PHPG. ${ }^{13}$ N-ammonia scans were also performed to compare resting perfusion patterns with regional innervation patterns. Eight subjects ( 8 males, ages $57 \pm 15$ y, range $37-75$ y) were recruited from our population of cardiomyopathy patients staged for ICD therapy. Inclusion criteria were: age $18-80$ y, cardiomyopathy (ischemic and nonischemic) and LVEF $<35 \%$. Exclusion criteria included: renal dysfunction, pregnancy or lactation, and concomitant medications interacting with sympathetic nerves (tricyclic antidepressants, phenylephrine, etc.). The study was approved by the University of Michigan Institutional Review Board and all subjects signed an informed consent document. The study was performed under an exploratory Investigational New Drug clearance from the US Food and Drug Administration and was registered at the ClinicalTrials.gov website (NCT02669563).

Radiotracer Production. ${ }^{18} \mathrm{~F}-4 \mathrm{~F}-\mathrm{MHPG}$ and ${ }^{18} \mathrm{~F}-3 \mathrm{~F}-\mathrm{PHPG}$ were prepared as previously reported [19], with radiochemical yields of $1.34 \pm 0.49 \mathrm{GBq}$ and $1.33 \pm 0.36 \mathrm{GBq}$, respectively. Radiochemical purities averaged $97.2 \% \pm 3.7 \%$ (range $90.7 \%-100 \%$ ) for ${ }^{18} \mathrm{~F}-4 \mathrm{~F}-\mathrm{MHPG}$ and $99.1 \% \pm 1.1 \%$ (range $98.5 \%-100 \%$ ) for ${ }^{18} \mathrm{~F}-3 \mathrm{~F}-\mathrm{PHPG}$. Molar activities averaged $109 \pm 54$ $\mathrm{GBq} / \mu \mathrm{mol}$ for ${ }^{18} \mathrm{~F}-4 \mathrm{~F}-\mathrm{MHPG}$ and $184 \pm 142 \mathrm{GBq} / \mu \mathrm{mol}$ for ${ }^{18} \mathrm{~F}-3 \mathrm{~F}-\mathrm{PHPG}$. 
PET/CT Data Acquisition and Processing. PET/CT scans were performed on a Siemens Biograph mCT scanner $(n=4)$ or a Siemens Biograph TruePoint TrueV scanner $(n=4)$, usually over two visits. On one day, an ${ }^{13} \mathrm{~N}$-ammonia scan was performed (740 MBq, 20 min dynamic imaging) followed $1 \mathrm{~h}$ later by an ${ }^{18} \mathrm{~F}-4 \mathrm{~F}-\mathrm{MHPG}$ or ${ }^{18} \mathrm{~F}-3 \mathrm{~F}-\mathrm{PHPG}$ scan. Scanning with the other innervation tracer was done on a different day. Doses of ${ }^{18} \mathrm{~F}-4 \mathrm{~F}-\mathrm{MHPG}$ averaged $255 \pm 2 \mathrm{MBq}$, containing masses averaging $0.74 \pm 0.31 \mu \mathrm{g}$ (range $0.29-1.29 \mu \mathrm{g}$ ). ${ }^{18} \mathrm{~F}-3 \mathrm{~F}-\mathrm{PHPG}$ injections averaged $253 \pm 5 \mathrm{MBq}$, with masses averaging $0.66 \pm 0.55 \mu \mathrm{g}$ (range 0.22-1.72 $\mu \mathrm{g}$ ). Dynamic PET data (60 min) were binned into a 24 -frame sequence $(12 \times 10,2 \times 30,2 \times 60,2 \times 150,2 \times 300$, and $4 \times 600 \mathrm{~s})$. During the innervation scans, six venous blood samples ( $2 \mathrm{~mL}$ each) were drawn to determine tracer metabolism in plasma and partitioning of activity between plasma and red blood cells, as previously described [18]. Images were reconstructed using iterative OSEM with 4 iterations and 14 subsets (TruePoint scanner) or 4 iterations and 12 subsets (mCT scanner) and smoothed with a $5 \mathrm{~mm}$ Gaussian filter.

Image Analysis. Using PMOD software (v3.8, PMOD Technologies, Zürich, Switzerland), cardiac PET data were reoriented and short-axis images interpolated into 4-mm slices. The left ventricular wall on the final PET frame was divided into 60 angular sectors using an algorithm written in IDL (v6.2, Harris Geospatial Solutions, Broomfield, CO). Using 18 short-axis slices encompassing the left ventricle, $18 \times 60=1080$ volumes-of-interest (VOIs) were defined, and tissue time-activity curves $C_{\mathrm{t}}(t)$ were extracted from the dynamic PET data. A whole-blood timeactivity curve $C_{\mathrm{wb}}(t)$ was obtained from a VOI placed in the left ventricular blood pool. 
Blood sample analysis. Six venous blood samples $(\sim 2 \mathrm{~mL}$ each $)$ were drawn and processed to provide purified plasma as previously described [20]. Target sample times were $t=2,5,8,15,30$ and $50 \mathrm{~min}$ for ${ }^{18} \mathrm{~F}-4 \mathrm{~F}-\mathrm{MHPG}$ and $t=4,8,12,20,35,50 \mathrm{~min}$ for ${ }^{18} \mathrm{~F}-3 \mathrm{~F}-\mathrm{PHPG}$. Radio-HPLC analysis of the purified plasma aliquots $(100-300 \mu \mathrm{L})$ determined the fraction of plasma activity associated with intact radiotracer, $f_{\text {intact }}(t)$. The $f_{\text {intact }}(t) v s$. time data were fit to dose-response functions (using GraphPad Prism v3.03) as previously described [21]. Whole-blood and plasma aliquots $(100 \mu \mathrm{L})$ were counted in a gamma counter to measure the plasma to whole-blood activity concentration ratio, $C_{\mathrm{p}} / C_{\mathrm{wb}}$. Since this tended to be constant through a study, the mean concentration ratio $\overline{C_{\mathrm{p}} / C_{\mathrm{wb}}}$ was calculated. A plasma time-activity curve, $C_{\mathrm{p}}(t)$, was estimated from the whole-blood curve as: $C_{\mathrm{p}}(t)=f_{\text {intact }}(t) \cdot\left(\overline{C_{\mathrm{p}} / C_{\mathrm{wb}}}\right) \cdot C_{\mathrm{wb}}(t)$.

Tracer kinetic analysis. For ${ }^{18}$ F-4F-MHPG and ${ }^{18}$ F-3F-PHPG, Patlak plots were constructed using the tissue and plasma time-activity curves and analyzed with linear regression to generate regional estimates of the Patlak slope, $K_{\mathrm{p}}(\mathrm{mL} / \mathrm{min} / \mathrm{g})$ and the linear regression coefficient $r$, as previously described [18]. Regression analysis used data from the $4.5 \mathrm{~min}$ frame to final frame of the study (frame mid-time $55 \mathrm{~min}$ in most cases, $35 \mathrm{~min}$ for Subject \#1). Polar maps of the Patlak slopes were generated to map regional sympathetic nerve densities. ${ }^{13} \mathrm{~N}$-ammonia kinetics were analyzed using the DeGrado method [22], as implemented in the PMOD Kinetic Modeling (PKIN) module, to obtain regional perfusion estimates, $F(\mathrm{~mL} / \mathrm{min} / \mathrm{g})$. Using the quantitative polar map data, the fraction of left ventricular VOIs with perfusion or nerve density metrics less than a cutoff threshold of $50 \%$ of their maximum map value were calculated to estimate the extent of left ventricular hypoperfusion and sympathetic denervation. 
Tracer retention measures. To compare the Patlak results to methods used for ${ }^{11} \mathrm{C}-\mathrm{HED}$, tracer 'retention index' (RI) metrics for ${ }^{18} \mathrm{~F}-4 \mathrm{~F}-\mathrm{MHPG}$ and ${ }^{18} \mathrm{~F}-3 \mathrm{~F}-\mathrm{PHPG}$ were calculated by dividing the final tracer tissue concentration $C_{\mathrm{t}}$ in each VOI by the integral of the whole blood time-activity curve, $C_{\mathrm{wb}}(t)$, as previously described [23]. This was done using the Tracer Retention algorithm in the PMOD Kinetic Modeling (PKIN) module. Using RI polar maps, the fraction of VOIs with RI values less than a cutoff threshold of 50\% of the maximum RI value was calculated as a measure of the extent of cardiac sympathetic denervation.

Safety and Tolerability Tests. Safety tests of ${ }^{18}$ F-4F-MHPG and ${ }^{18}$ F-3F-PHPG were performed before and after each PET session, including a resting 12-lead ECG and measurements of heart rate, blood pressure, respiration and body temperature. Blood tests (comprehensive metabolic panel, complete blood count, and plasma catecholamine levels) and urinalysis were also performed. Heart rate and peripheral capillary oxygen saturation $\left(\mathrm{SpO}_{2}\right)$ were continuously monitored during PET scanning, and blood pressure measured every $10 \mathrm{~min}$. Subjects were contacted at $24 \mathrm{~h}$ and 30 days to enquire about any adverse events.

Statistical Analysis. Statistical calculations were performed using Microsoft Excel 2016.

\section{RESULTS}

Subject Characteristics. Clinical information for the subjects is summarized in Table 1. Six subjects had ischemic cardiomyopathy with prior myocardial infarction. The other two had a diagnosis of nonischemic cardiomyopathy with no known prior infarctions. None of the eight patients had mixed etiology. 
Safety. ${ }^{18}$ F-4F-MHPG and ${ }^{18}$ F-3F-PHPG were well tolerated in all subjects. No significant changes in vital signs were observed during PET scanning, and there were no effects on ECG data or laboratory test results. No adverse events were reported.

PET Imaging. Seven of the eight subjects completed all three PET scans. One subject (\#1) ended their innervation PET scans early (at $t=40 \mathrm{~min}$ ) due to discomfort in the scanner. Another subject (\#3) left the study after completing scans with ${ }^{13} \mathrm{~N}$-ammonia and ${ }^{18} \mathrm{~F}-4 \mathrm{~F}-\mathrm{MHPG}$. Representative PET/CT scans are shown in Figure 1. ${ }^{18} \mathrm{~F}-4 \mathrm{~F}-\mathrm{MHPG}$ and ${ }^{18} \mathrm{~F}-3 \mathrm{~F}-\mathrm{PHPG}$ produced high quality cardiac PET images, with low lung uptake and good heart-to-blood contrast. More prolonged retention of ${ }^{18} \mathrm{~F}-3 \mathrm{~F}-\mathrm{PHPG}$ in the liver relative to ${ }^{18} \mathrm{~F}-4 \mathrm{~F}-\mathrm{MHPG}$ is evident in the coronal images.

Tissue Concentration Ratios. Tissue concentrations for peak heart uptake and mean concentrations in blood, liver and lung were determined in the last five image frames to calculate the tissue concentration ratios: peak heart-to-liver, peak heart-to-blood and peak heart-to-lung (Figure 2). ${ }^{18}$ F-4F-MHPG exhibited significantly higher peak heart-to-liver ratios at all five times, increasing from $1.57 \pm 0.29$ at $17.5 \mathrm{~min}$ to $2.55 \pm 0.35$ at $55 \mathrm{~min}$, compared with $0.75 \pm 0.25$ to $1.15 \pm 0.40$ for ${ }^{18} \mathrm{~F}-3 \mathrm{~F}-\mathrm{PHPG}$ (Figure $2 \mathrm{~A}$; paired $t$-test $p<0.007$ at all times, range 0.0005 to 0.007). Peak heart-to-liver ratios for ${ }^{18} \mathrm{~F}-4 \mathrm{~F}-\mathrm{MHPG}$ over those of ${ }^{18} \mathrm{~F}-3 \mathrm{~F}-\mathrm{PHPG}$ were consistently 2.2 times higher $(2.2 \pm 0.1)$. Conversely, ${ }^{18} \mathrm{~F}-3 \mathrm{~F}-\mathrm{PHPG}$ had significantly higher peak heart-toblood ratios at all times, with final frame values of $13.4 \pm 6.7$ compared to $7.6 \pm 2.8$ for ${ }^{18} \mathrm{~F}-4 \mathrm{~F}-$ MHPG (Figures 2B; $p<0.04$ at all times, range 0.003 to 0.04 ), averaging about 1.8 times higher at each time point $(1.8 \pm 0.1) .{ }^{18} \mathrm{~F}-3 \mathrm{~F}-\mathrm{PHPG}$ also had consistently higher peak heart-to-lung ratios 
(Figure 2C; $p<0.02$ (range 0.007 to 0.02 , significant at all times except at $55 \mathrm{~min}$, where $p<$ 0.09). Peak heart-to-lung ratios of ${ }^{18} \mathrm{~F}-3 \mathrm{~F}-\mathrm{PHPG}$ were $40 \%$ higher at each time point than those of ${ }^{18}$ F-4F-MHPG $(1.4 \pm 0.0)$.

Blood Sample Analysis. Metabolic breakdown of ${ }^{18} \mathrm{~F}-4 \mathrm{~F}-\mathrm{MHPG}$ and ${ }^{18} \mathrm{~F}-3 \mathrm{~F}-\mathrm{PHPG}$ in plasma was biphasic (Figure 3). A large fraction of ${ }^{18} \mathrm{~F}-4 \mathrm{~F}-\mathrm{MHPG}$ is rapidly metabolized in the initial phase, with times of $50 \%$ metabolized $\left(T_{50 \%}\right)$ averaging $5.7 \pm 1.1 \mathrm{~min} .{ }^{18} \mathrm{~F}-3 \mathrm{~F}-\mathrm{PHPG}$ metabolism was significantly slower (paired two-tailed $t$-test $p<0.01$ ) and more variable, with $T_{50 \%}$ values averaging $11.2 \pm 4.3 \mathrm{~min}$. Plasma to whole blood ratios, $C_{\mathrm{p}} / C_{\mathrm{wb}}$, were consistent within a given subject, ranging from $1.32 \pm 0.10$ to $1.82 \pm 0.15$ for ${ }^{18} \mathrm{~F}-4 \mathrm{~F}-\mathrm{MHPG}$ and from $1.34 \pm 0.06$ to $1.67 \pm$ 0.09 for ${ }^{18} \mathrm{~F}-3 \mathrm{~F}-\mathrm{PHPG}$. Across subjects, $C_{\mathrm{p}} / C_{\mathrm{wb}}$ averaged $1.45 \pm 0.18$ for ${ }^{18} \mathrm{~F}-4 \mathrm{~F}-\mathrm{MHPG}$ and 1.48 \pm 0.15 for ${ }^{18} \mathrm{~F}-3 \mathrm{~F}-\mathrm{PHPG}$.

Tracer Kinetic Analysis. Patlak analysis of ${ }^{18} \mathrm{~F}-4 \mathrm{~F}-\mathrm{MHPG}$ and ${ }^{18} \mathrm{~F}-3 \mathrm{~F}-\mathrm{PHPG}$ kinetics was successful in all left ventricular regions for all subjects. Figure 4B shows examples of ${ }^{18} \mathrm{~F}-3 \mathrm{~F}-$ PHPG kinetics in regions covering a range of nerve densities along with corresponding Patlak plots (Figure 4C). Highly linear fits of the Patlak plot data were obtained, independent of the degree of denervation. Linear correlation coefficients $r$ (mean \pm SD within a subject) ranged from $0.965 \pm 0.025$ to $0.995 \pm 0.003$ for ${ }^{18} \mathrm{~F}-4 \mathrm{~F}-\mathrm{MHPG}$ and from $0.990 \pm 0.009$ to $0.995 \pm 0.005$ for ${ }^{18} \mathrm{~F}-$ 3F-PHPG. Patlak slopes and resting perfusion values are presented in Table 2. Plots illustrating the distribution of the regional Patlak slopes in each subject are provided in Figure 5. All subjects had some regions with Patlak slopes in the normal range, representing regions with preserved innervation, as well as regions with Patlak slopes below normal, consistent with partial or complete 
denervation. Within subjects, regional Patlak slopes measured for ${ }^{18} \mathrm{~F}-3 \mathrm{~F}-\mathrm{PHPG}$ and ${ }^{18} \mathrm{~F}-4 \mathrm{~F}-$ MHPG were highly correlated, with linear correlation coefficients $r$ ranging from 0.911 to 0.985 (Figure 6). Threshold analysis of resting perfusion estimates and Patlak slopes for ${ }^{18} \mathrm{~F}-4 \mathrm{~F}-\mathrm{MHPG}$ and ${ }^{18}$ F-3F-PHPG, using a conservative cutoff threshold of $50 \%$ of the maximum value, provided measures of the extent of left ventricular hypoperfusion and denervation (Table 3). Polar map examples are provided in Figure 7. Denervation extent measures for ${ }^{18} \mathrm{~F}-4 \mathrm{~F}-\mathrm{MHPG}$ and ${ }^{18} \mathrm{~F}-3 \mathrm{~F}-$ PHPG closely agreed in most subjects, and differed by less than $5 \%$ for all subjects.

Tracer Retention Analysis. Retention index (RI) values and denervation extent estimates obtained using a cutoff threshold of $50 \%$ of the maximum RI value are shown in Table 4 . Within individuals, there was strong linear correlation between regional RI values and Patlak slopes, $K_{\mathrm{p}}$, with linear correlation coefficients $r>0.991$ in all cases for both tracers. This is not surprising since areas with higher Patlak slopes will result in higher amounts of tracer trapped in neurons, leading to higher tracer retention values. However, the slopes of the correlations were variable across subjects, ranging widely from 0.41 to 0.89 for ${ }^{18} \mathrm{~F}-4 \mathrm{~F}-\mathrm{MHPG}$ and from 0.64 to 1.11 for ${ }^{18} \mathrm{~F}$ 3F-PHPG. These correlation slopes would be expected to depend largely on the rate of tracer metabolism in each individual, since RI values are normalized to the integral of the whole-blood time-activity curve, uncorrected for metabolites. Thus, correlation slopes should be lower in subjects with faster tracer metabolism rates, which would lead to lower RI values than those in subjects with slower metabolism rates. Regression analysis with two metrics of tracer metabolism rates support this. First, the RI $v s . K_{\mathrm{p}}$ correlation slopes and subject half-times of tracer metabolism (Figure 3) were significantly correlated, with $R^{2}=0.561(p<0.03)$ and $R^{2}=0.956(p<0.0001)$ for ${ }^{18} \mathrm{~F}-4 \mathrm{~F}-\mathrm{MHPG}$ and ${ }^{18} \mathrm{~F}-3 \mathrm{~F}-\mathrm{PHPG}$, respectively. The slopes were also significantly correlated 
with the area under the metabolism curve (from numerical integration using GraphPad Prism v3.03), with $R^{2}=0.686(p<0.01)$ for ${ }^{18} \mathrm{~F}-4 \mathrm{~F}-\mathrm{MHPG}$ and $R^{2}=0.918(p<0.0007)$ for ${ }^{18} \mathrm{~F}-3 \mathrm{~F}-$ PHPG. Linear regression of the mean RI value for each subject $v$ s. their corresponding mean Patlak slope $\left(K_{\mathrm{p}}\right)$ gave: $\mathrm{RI}=(0.533) K_{\mathrm{p}}+0.004$ for ${ }^{18} \mathrm{~F}-4 \mathrm{~F}-\mathrm{MHPG}$, which was not significant $\left(R^{2}\right.$ $=0.368, p<0.1)$. For ${ }^{18}$ F-3F-PHPG, the relationship was: $\mathrm{RI}=(1.282) K_{\mathrm{p}}-0.035$, which reached significance $\left(R^{2}=0.671, p<0.02\right)$. The higher slope of the relationship for ${ }^{18} \mathrm{~F}-3 \mathrm{~F}-\mathrm{PHPG}$ is also tied to its slower metabolism in plasma than ${ }^{18}$ F-4F-MHPG. Finally, denervation extent estimates made using threshold analysis of RI values were in close agreement with those obtained from Patlak slopes (Figures 8A, 8B). Strong linear correlations between the denervation extent metrics obtained from RI values and Patlak slopes were seen for both tracers (Figure 8C), with $R^{2}=0.996$ $\left(p<2 \times 10^{-8}\right)$ for ${ }^{18} \mathrm{~F}-4 \mathrm{~F}-\mathrm{MHPG}$ and $R^{2}=0.995\left(p<5 \times 10^{-7}\right)$ for ${ }^{18} \mathrm{~F}-3 \mathrm{~F}-\mathrm{PHPG}$.

\section{DISCUSSION}

First-in-human studies of ${ }^{18} \mathrm{~F}-4 \mathrm{~F}-\mathrm{MHPG}$ and ${ }^{18} \mathrm{~F}-3 \mathrm{~F}-\mathrm{PHPG}$ in healthy subjects demonstrated that their irreversible kinetics can be analyzed with Patlak analysis to estimate regional cardiac sympathetic nerve density, with Patlak slopes averaging $0.107 \pm 0.010 \mathrm{~mL} / \mathrm{min} / \mathrm{g}$ and $0.116 \pm$ $0.010 \mathrm{~mL} / \mathrm{min} / \mathrm{g}$, respectively [18]. The first studies of ${ }^{18} \mathrm{~F}-4 \mathrm{~F}-\mathrm{MHPG}$ and ${ }^{18} \mathrm{~F}-3 \mathrm{~F}-\mathrm{PHPG}$ in cardiomyopathy patients reported here show they can also provide quantitative nerve density measures in hearts with extensive disease-induced denervation. Their administration caused no changes in blood pressure, heart rate, ECG measures, or laboratory tests, and caused no adverse events, further establishing their safety.

Comparing ${ }^{18} \mathrm{~F}-4 \mathrm{~F}-\mathrm{MHPG}$ and ${ }^{18} \mathrm{~F}-3 \mathrm{~F}-\mathrm{PHPG}$, each agent demonstrated an advantage over the other. ${ }^{18}$ F-4F-MHPG exhibited significantly higher heart-to-liver ratios due to its faster clearance from the liver, providing better heart-to-background contrast and reducing spillover from the liver 
into adjacent ventricular regions (Figure 1, Figure 2). ${ }^{18} \mathrm{~F}-3 \mathrm{~F}-\mathrm{PHPG}$ had consistently higher heartto-blood ratios, due to its moderately lower blood concentrations and its slower metabolism in plasma, which increased myocardial concentrations. While ${ }^{18}$ F-3F-PHPG metabolism in plasma was slower than ${ }^{18} \mathrm{~F}-4 \mathrm{~F}-\mathrm{MHPG}$, its metabolism was also much more variable across individuals (Figure 3). The cause of this is unknown, but could be related to medication effects in the liver. A potential advantage of the more consistent metabolic breakdown of ${ }^{18} \mathrm{~F}-4 \mathrm{~F}-\mathrm{MHPG}$ is that it may allow the application of population-averaged metabolite corrections for generating input functions, eliminating the need for blood sampling. In kinetic analyses, regional Patlak slopes obtained with ${ }^{18}$ F-4F-MHPG and ${ }^{18}$ F-3F-PHPG were highly correlated in all subjects (example in Figure 6), and there was also very good agreement between each tracer's estimate of the extent of left ventricular denervation (Table 3). Thus the two tracers are essentially equivalent in their ability to quantify regional nerve densities using Patlak analysis.

${ }^{18} \mathrm{~F}-4 \mathrm{~F}-\mathrm{MHPG}$ and ${ }^{18} \mathrm{~F}-3 \mathrm{~F}-\mathrm{PHPG}$ accumulate in cardiac sympathetic nerve varicosities as substrates of the norepinephrine transporter (NET) and are rapidly stored in norepinephrine storage vesicles by the second isoform of the vesicular monoamine transporter (VMAT2). Efficient retention in storage vesicles is the mechanism responsible for their irreversible tissue kinetics [16]. Our results show that ${ }^{18} \mathrm{~F}-4 \mathrm{~F}-\mathrm{MHPG}$ and ${ }^{18} \mathrm{~F}-3 \mathrm{~F}-\mathrm{PHPG}$ retain their irreversible kinetics in patients with cardiomyopathy, including cardiac regions with severe nerve losses. This is an important finding since vesicular storage function, an energy-dependent process, can be compromised during acute ischemia. Vesicular storage of norepinephrine requires sufficient ATP concentrations to maintain the proton electrochemical gradient that drives VMAT2 transport [24]. Energy depletion during acute ischemia causes substantial release of norepinephrine from nerve terminals, as vesicles lose their ability to retain norepinephrine due to the collapse of the proton potential 
normally maintained by ATP [25]. Thus, the observation that ${ }^{18}$ F-4F-MHPG and ${ }^{18} \mathrm{~F}-3 \mathrm{~F}-\mathrm{PHPG}$ maintain their irreversible kinetics in regions with substantial nerve losses indicates that vesicular storage function remains intact in the surviving neurons of patients with chronic cardiomyopathy.

An advantage of Patlak analysis is it only requires linear regression of the transformed kinetic data, a robust method that can be applied to small region sizes. In preclinical PET studies in nonhuman primates with ${ }^{18} \mathrm{~F}-4 \mathrm{~F}-\mathrm{MHPG}$, measured Patlak slopes provided good reproducibility ( $\pm 10 \%$ or less) under control conditions [15]. Also, pharmacological blocking studies tested the ability of the Patlak slopes to track cardiac denervation by varying the fraction of available cardiac NET transporters by infusing different doses of the potent NET inhibitor desipramine (DMI) intravenously prior to tracer administration. Patlak slopes declined with increasing DMI doses following a sigmoidal dose-response model, showing that they sensitively tracked the declines in available NET. At the highest doses of DMI $(1.0 \mathrm{mg} / \mathrm{kg})$, blood activity exceeded activity in the myocardium, consistent with complete blockade of NET. This demonstrates the high specificity of ${ }^{18} \mathrm{~F}-4 \mathrm{~F}-\mathrm{MHPG}$ for presynaptic sympathetic nerve varicosities.

The side-by-side presentation of perfusion and innervation polar maps (Figure 7) illustrates how nuclear cardiologists could compare the pattern and extent of sympathetic denervation with regional perfusion to assess SCD risk. Evidence suggests that zones of denervated myocardium that are well perfused ('perfusion-innervation mismatch' zones) are areas that promote the genesis of ventricular arrhythmias [26]. In this study, five of the eight subjects had denervation zones that were larger than their extent of hypoperfusion. All five of these subjects had ischemic cardiomyopathy with prior myocardial infarctions. Conversely, two subjects with matched hypoperfusion and denervation zones had nonischemic cardiomyopathy and no prior infarctions. Whether this pattern difference between ischemic and nonischemic cardiomyopathy would be a 
consistent finding in a larger cohort remains to be seen, since the PAREPET trial excluded patients with nonischemic cardiomyopathy. However, PAREPET evaluated the predictive value of a perfusion-innervation mismatch metric measured with ${ }^{13} \mathrm{~N}$-ammonia and ${ }^{11} \mathrm{C}-\mathrm{HED}$. While the mismatch metric demonstrated power in predicting arrhythmic risk, the denervation extent measure alone was found to be a stronger predictor of sudden cardiac arrest [14].

Clinical studies with ${ }^{123} \mathrm{I}-\mathrm{mIBG}$ and ${ }^{11} \mathrm{C}-\mathrm{HED}$ generally rely on semi-quantitative metrics of tracer retention, such as the H/M ratio for ${ }^{123} \mathrm{I}-\mathrm{mIBG}$ or 'retention index' (RI) values for ${ }^{11} \mathrm{C}-\mathrm{HED}$, as measures of global or regional sympathetic nerve density, respectively $[9,13]$. While these measures have served as useful first approaches to quantifying nerve losses, a PET radiotracer that can accurately quantify regional nerve density using tracer kinetic analysis methods is desirable, not only for routine clinical studies in patients, but also for research on the impact of diseases on cardiac nerve populations [27]. In this study, we compared the measures of sympathetic nerve density and the extent of left ventricular denervation obtained with Patlak analysis with those obtained with the RI value approach frequently used for ${ }^{11} \mathrm{C}$-HED. While regional RI values were highly correlated with regional Patlak slopes within individual subjects, the slopes of these correlations varied considerably with tracer metabolism rates in plasma. Because individual tracer metabolism rates are unaccounted for in the RI calculation itself, there is variation in the calculated RI values across individuals that limits their utility as metrics of nerve density on an absolute scale. However, our results showed that estimates of the extent of left ventricular denervation using threshold analysis of RI polar maps were within a few percent of those obtained using the Patlak slope data (Figure 8). Therefore, if the sole purpose of a clinical PET study with ${ }^{18}$ F-4F-MHPG or ${ }^{18} \mathrm{~F}-3 \mathrm{~F}-\mathrm{PHPG}$ is to obtain an estimate of the extent of sympathetic denervation, using the RI approach with these new tracers would be adequate for this purpose. On the other hand, if the goal 
was to obtain quantitative measures of regional nerve density, in addition to the denervation extent measure, Patlak analysis would be the superior method. Thus, these tracers offer clinicians the choice of performing quantitative innervation studies using Patlak analysis, or for studies focused solely on estimating the extent of cardiac denervation, the RI approach, which avoids the need for blood sample analysis.

Limitations of this study include the small number of subjects and the absence of female subjects in the study cohort, which limits its generalizability to all cases of cardiomyopathy.

\section{CONCLUSION}

In conclusion, ${ }^{18} \mathrm{~F}-4 \mathrm{~F}-\mathrm{MHPG}$ and ${ }^{18} \mathrm{~F}-3 \mathrm{~F}-\mathrm{PHPG}$ are two new radiotracers that can each be used to quantify sympathetic nerve density at high regional resolution using Patlak analysis, a unique attribute that distinguishes them from existing cardiac innervation tracers. Nerve density and cardiac denervation extent measures obtained with the two agents were similar in all cardiomyopathy subjects tested. While each agent has its own advantages, comparisons of the properties of the two tracers suggest that ${ }^{18} \mathrm{~F}-4 \mathrm{~F}-\mathrm{MHPG}$, with its more rapid clearance from the liver and more consistent metabolism in plasma, is the better agent to carry forward into future clinical studies. Our results support the performance of a larger clinical trial in the future to establish the power of the nerve density and denervation extent metrics obtained with ${ }^{18} \mathrm{~F}-4 \mathrm{~F}-$ MHPG to predict SCD risk, and in turn, its usefulness for risk stratification of patients for ICD placement. 


\section{ACKNOWLEDGMENTS}

We thank Dr. Peter Scott, Brian Hockley, Bradford Henderson and Charles Schneider in the University of Michigan PET Radiopharmaceutical Production program for their support in synthesizing the radiotracers. We also thank our clinical research coordinators Eric Puroll, James Pool, Mary Burton and Tamara Harper for their many contributions.

\section{DECLARATIONS}

\section{Compliance with Ethical Standards:}

Funding: This study was funded by a Mid-Stage Award (MTRAC-N019131) from the University of Michigan Fast Forward Medical Innovation (FFMI) Program and through a Services Award (RSA-000169) from the Science Moving Towards Research Translation and Therapy (SMARTT) Program of the National Heart, Lung and Blood Institute, National Institutes of Health, Bethesda, MD, USA.

Conflict of interest. The authors have no relevant financial or non-financial interests to disclose.

Ethical approval: The study was approved by the University of Michigan Institutional Review Board (HUM00105110). This article does not contain any studies with animals performed by any of the authors. All procedures performed in studies involving human participants were in accordance with the ethical standards of the institutional and/or national research committee and with the 1964 Helsinki declaration and its later amendments or comparable ethical standards.

Informed consent: Informed consent was obtained from all individual participants included in the study. 


\section{REFERENCES}

1. Adabag AS, Luepker RV, Roger VL, Gersh BJ. Sudden cardiac death: epidemiology and risk factors. Nat Rev Cardiol. 2010;7:216-25.

2. Saour B, Smith B, Yancy CW. Heart failure and sudden cardiac death. Card Electrophysiol Clin. 2017;9:709-23.

3. Buxton AE, Waks JW, Shen C, Chen P-S. Risk stratification for sudden cardiac death in North America -- current perspectives. J Electrocard. 2016;49:817-23.

4. Passman R, Goldberger JJ. Predicting the future: risk stratification for sudden cardiac death in patients with left ventricular dysfunction. Circulation. 2012;125:3013-37.

5. Koneru JN, Swerdlow CD, Wood MA, Ellenbogen KA. Minimizing inappropriate or "unnecessary" implantable cardioverter-defibrillator shocks: appropriate programming. Circ Arrhythm Electrophysiol. 2011;4:778-90.

6. Deyell MW, Krahn AD, Goldberger JJ. Sudden cardiac death risk stratification. Circ Res. 2015;116:1907-18.

7. Gardner RT, Ripplinger CM, Myles RC, Habecker BA. Molecular mechanisms of sympathetic remodeling and arrhythmias. Circ Arrhythm Electrophysiol. 2016;9:e001359. doi:10.1161/CIRCEP.115.001359.

8. Srinivasa NT, Schilling RJ. Sudden cardiac death and arrhythmias. Arrhythm Electrophysiol Rev. 2018;7:111-7.

9. Allman KC, Wieland DM, Muzik O, Degrado TR, Wolfe ER, Schwaiger M. Carbon-11 hydroxyephedrine with positron emission tomography for serial assessment of cardiac adrenergic neuronal function after acute myocardial infarction in humans. J Am Coll Cardiol. 1993;22:368-75.

10. Chen LS, Zhou S, Fishbein MC, Chen P-S. New perspectives on the role of autonomic nervous system in the genesis of arrythmias. J Cardiovasc Electrophysiol. 2007;18:123-7.

11. Rubart M, Zipes DP. Mechanisms of sudden cardiac death. J Clin Invest. 2005;115:2305-15.

12. Ogawa M, Zhou S, Tan AY, Fishbein MC, Lin S-F, Chen LS, et al. What have we learned about the contribution of autonomic nervous system to human arrhythmia? Heart Rhythm. 2009;6:S8-S11.

13. Jacobson AF, Senior R, Cerqueira MD, Wong ND, Thomas GS, Lopez VA, et al. Myocardial iodine123 meta-iodobenzylguanidine imaging and cardiac events in heart failure: results of the prospective ADMIRE-HF (AdreView Myocardial Imaging for Risk Evaluation in Heart Failure) study. J Am Coll Cardiol. 2010;55:2212-21.

14. Fallavollita JA, Heavey BM, Luisi AJ, Michalek SM, Baldwa S, Mashtare TL, et al. Regional myocardial sympathetic denervation predicts the risk of sudden cardiac arrest in ischemic cardiomyopathy. J Am Coll Cardiol. 2014;63:141-9.

15. Jang KS, Jung YW, Gu G, Koeppe RA, Sherman PS, Quesada CA, et al. 4-[ $\left[{ }^{18}\right.$ F]fluoro-mhydroxyphenethylguanidine: a radiopharmaceutical for quantifying regional cardiac sympathetic nerve density with positron emission tomography. J Med Chem. 2013;56:7312-23.

16. Raffel DM, Jung YW, Gildersleeve DL, Sherman PS, Moskwa JJ, Tluczek LJ, et al. Radiolabeled phenethylguanidines: novel imaging agents for cardiac sympathetic neurons and adrenergic tumors. J Med Chem. 2007;50:2078-88.

17. Patlak CS, Blasberg RG. Graphical evaluation of blood-to-brain transfer constants from multipletime uptake data. Generalizations. J Cereb Blood Flow. 1985;5:584-90. 
18. Raffel DM, Jung YW, Koeppe RA, Jang KS, Gu G, Scott PJH, et al. First-in-human studies of $\left[{ }^{18} \mathrm{~F}\right]$ fluorohydroxyphenethylguanidines: positron emission tomography radiotracers for quantifying regional cardiac sympathetic nerve density. Circ Cardiovasc Imaging. 2018;11:e007965.

19. Jung YW, Jang KS, Gu G, Koeppe RA, Sherman PS, Quesada CA, et al. [ ${ }^{18}$ F]Fluorohydroxyphenethylguanidines: efficient synthesis and comparison of two structural isomers as radiotracers of cardiac sympathetic innervation. ACS Chem Neurosci. 2017;8:1530-42. doi:10.1021/acschemneuro.7b00051.

20. Jang KS, Jung YW, Sherman PS, Quesada CA, Gu G, Raffel DM. Synthesis and bioevaluation of $\left[{ }^{18} \mathrm{~F}\right] 4$-fluoro- $m$-hydroxyphenethylguanidine $\left(\left[{ }^{18} \mathrm{~F}\right] 4 \mathrm{~F}-\mathrm{MHPG}\right)$ : a novel radiotracer for quantitative PET studies of cardiac sympathetic innervation. Bioorg Med Chem Lett. 2013;23:1612-6.

21. Raffel DM, Koeppe RA, Jung YW, Gu G, Jang KS, Sherman PS, et al. Quantification of cardiac

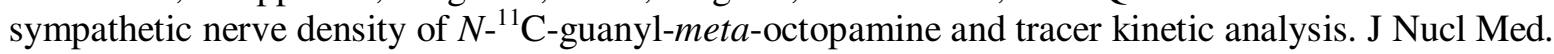
2013;54:1645-52.

22. DeGrado TR, Hanson MW, Turkington TG, Delong DM, Brezinski DA, Vallée JP, et al. Estimation of myocardial blood flow for longitudinal studies with ${ }^{13} \mathrm{~N}$-labeled ammonia and positron emission tomography. J Nucl Cardiol. 1996;3:494-507.

23. Raffel DM, Corbett JR, del Rosario RB, Gildersleeve DL, Chiao PC, Schwaiger M, et al. Clinical evaluation of carbon-11-phenylephrine: MAO sensitive marker of cardiac sympathetic neurons. J Nucl Med. 1996;37:1923-31.

24. Anne C, Gasnier B. Vesicular neurotransmitter transporters: mechanistic aspects. Curr Top Membr. 2014;73:149-74.

25. Kurz T, Richardt G, Hagl S, Seyfarth M, Schömig A. Two different mechanisms of noradrenaline release during normoxia and simulated ischemia in human cardiac tissue. J Mol Cell Cardiol. 1995;27:1161-72.

26. Simões MV, Barthel P, Matsunari I, Nekolla SG, Schömig A, Schwaiger M, et al. Presence of sympathetically denervated but viable myocardium and its electrophysiologic correlates after early revascularised, acute myocardial infarction. Eur Heart J. 2004;25:551-7.

27. Bengel FM. Imaging of myocardial catecholamine uptake: toward robust absolute quantification [editorial]. Circ Cardiovasc Imaging. 2018;11:e008534. doi:10.1161/CIRCIMAGING.118.008534. 


\section{FIGURE CAPTIONS}

Fig. 1 Representative final transaxial (top row) and coronal (bottom row) fused PET/CT images (Subject \#6)

Fig. 2 Mean tissue activity concentration ratios for peak heart-to-liver (A), peak heart-to-blood (B) and peak heart-to-lung $(\mathbf{C})$ in the last five PET image frames.

Fig. 3 Metabolism of ${ }^{18}$ F-4F-MHPG (left) and ${ }^{18}$ F-3F-PHPG (right) in plasma. Mean times at which $50 \%$ of plasma activity remains as intact radiotracer $\left(T_{50 \%}\right)$ are shown (mean $\left.\pm \mathrm{SD}\right)$

Fig. 4 (A) ${ }^{18}$ F-3F-PHPG image for Subject \#1 showing VOI locations of representative kinetic data. (B) ${ }^{18}$ F-3F-PHPG kinetics in regions with different sympathetic nerve densities, from normal (red) down to severe denervation (violet). (C) Corresponding Patlak plots for the kinetic data shown in $(\mathbf{B})$, demonstrating the decline of the Patlak slope with decreasing nerve density. $\mathrm{VOI}=$ volume-of-interest

Fig. 5 Distribution of regional Patlak slopes in each subject for (A) ${ }^{18} \mathrm{~F}-4 \mathrm{~F}-\mathrm{MHPG}$ and (B) ${ }^{18} \mathrm{~F}-$ 3F-PHPG. The normal range of Patlak slopes is illustrated by a black line representing the mean Patlak slopes measured previously in healthy control subjects and a gray shaded area representing $\pm 2 \times \mathrm{SD}$ around the normal mean. Red lines represent the mean Patlak slope for each subject

Fig. 6 Plot of regional Patlak slopes measured with ${ }^{18}$ F-3F-PHPG versus ${ }^{18}$ F-4F-MHPG in Subject \#1, showing a high linear correlation $(r=0.985) . r=$ linear correlation coefficient 
Fig. 7 Representative polar maps of resting perfusion measured with ${ }^{13} \mathrm{~N}$-ammonia and Patlak slopes as metrics of regional sympathetic nerve density measured with ${ }^{18} \mathrm{~F}-4 \mathrm{~F}-\mathrm{MHPG}$ and ${ }^{18} \mathrm{~F}-3 \mathrm{~F}-$ PHPG (top row). Corresponding maps with areas of hypoperfusion or denervation blacked out are shown below (bottom row) along with quantitative estimates of the extents of hypoperfusion or denervation. A: Subject \#1, age 74 y, BMI $=46$, NYHA class III, $\mathrm{LVEF}=18 \%$, with ischemic cardiomyopathy. B: Subject \#4, age 67 y, BMI = 23, NYHA Class I, LVEF $=35 \%$ with an anteroseptal myocardial infarction five months earlier. C: Subject \#5, age 37 y, BMI = 27, NYHA class $\mathrm{I}, \mathrm{LVEF}=22 \%$, with nonischemic cardiomyopathy. $\mathrm{BMI}=$ body mass index, NYHA $=\mathrm{New}$ York Heart Association, LVEF = left ventricular ejection fraction

Fig. 8 Comparison of extent of denervation metrics calculated using Patlak slopes and RI values for ${ }^{18}$ F-4F-MHPG (A) and ${ }^{18}$ F-3F-PHPG (B). Denervation extent measures obtained using RI values were linearly correlated with those obtained using Patlak slopes (C) 
TABLE 1. Subject Characteristics.

\begin{tabular}{|c|c|c|c|c|c|c|c|c|c|c|c|c|}
\hline $\begin{array}{c}\text { Subject } \\
\#\end{array}$ & $\begin{array}{c}\text { Age } \\
(\mathbf{y})\end{array}$ & $\begin{array}{c}\text { Weight } \\
(\mathbf{k g})\end{array}$ & BMI & $\begin{array}{c}\text { NYHA } \\
\text { Class }\end{array}$ & $\begin{array}{c}\text { LVEF } \\
(\boldsymbol{\%})\end{array}$ & $\begin{array}{c}\text { Prior } \\
\text { MI }\end{array}$ & $\begin{array}{c}\text { Prior } \\
\text { CABG }\end{array}$ & HTN & AF & ICM & NICM & Comments \\
\hline 1 & 74 & 120 & 34 & III & 18 & & $\checkmark$ & $\checkmark$ & $\checkmark$ & $\checkmark$ & & \\
\hline 2 & 39 & 138 & 46 & II & 15 & $\checkmark$ & $\checkmark$ & & & $\checkmark$ & & \\
\hline 3 & 60 & 104 & 35 & I & 25 & $\checkmark$ & & & & $\checkmark$ & & DM/Type 2 \\
\hline 4 & 67 & 78 & 23 & I & 35 & $\checkmark$ & & & & $\checkmark$ & & anteroseptal MI \\
\hline 5 & 37 & 85 & 27 & I & 22 & & & $\checkmark$ & $\checkmark$ & & $\checkmark$ & \\
\hline 6 & 43 & 80 & 28 & III & 18 & & $\checkmark$ & & & $\checkmark$ & & recent CABG-3× \\
\hline 7 & 61 & 79 & 24 & I & 25 & $\checkmark$ & $\checkmark$ & $\checkmark$ & & $\checkmark$ & & DM/Type 2 \\
\hline 8 & 73 & 109 & 31 & I & 21 & & & & & & $\checkmark$ & $\checkmark$ \\
\hline
\end{tabular}

BMI = body mass index, NYHA = New York Heart Association, LVEF = left ventricular ejection fraction, $\mathrm{MI}=$ myocardial infarction, $\mathrm{CABG}=$ coronary artery bypass grafting, $\mathrm{HTN}=$ hypertension, $\mathrm{AF}=$ atrial fibrillation, $\mathrm{ICM}=$ ischemic cardiomyopathy, NICM = nonischemic cardiomyopathy, $\mathrm{DM}=$ diabetes mellitus. 
TABLE 2. Global Parameter Estimates from Tracer Kinetic Analysis.

\begin{tabular}{|c|c|c|c|c|c|c|}
\hline Subject \# & $\begin{array}{c}{ }^{13} \mathrm{~N} \text {-Ammonia } \\
\text { Resting Perfusion } \\
\quad(\mathrm{mL} / \mathrm{min} / \mathrm{g})\end{array}$ & $\begin{array}{l}\text { CV } \\
(\%)\end{array}$ & $\begin{array}{c}{ }^{18} \text { F-4F-MHPG } \\
\text { Patlak Slopes } \\
(\mathrm{mL} / \mathrm{min} / \mathrm{g})\end{array}$ & $\begin{array}{l}\text { CV } \\
(\%)\end{array}$ & $\begin{array}{c}{ }^{18} \text { F-3F-PHPG } \\
\text { Patlak Slopes } \\
(\mathrm{mL} / \mathrm{min} / \mathrm{g})\end{array}$ & $\begin{array}{l}\text { CV } \\
(\%)\end{array}$ \\
\hline 1 & $0.468 \pm 0.126$ & $29.4 \%$ & $0.0632 \pm 0.0255$ & $40.3 \%$ & $0.0710 \pm 0.0346$ & $48.7 \%$ \\
\hline 2 & $0.522 \pm 0.168$ & $32.2 \%$ & $0.0542 \pm 0.0237$ & $43.7 \%$ & $0.0586 \pm 0.0268$ & $45.7 \%$ \\
\hline 3 & $0.446 \pm 0.215$ & $48.2 \%$ & $0.0419 \pm 0.0256$ & $61.1 \%$ & - & - \\
\hline 4 & $0.690 \pm 0.139$ & $20.1 \%$ & $0.0626 \pm 0.0285$ & $45.5 \%$ & $0.0766 \pm 0.0374$ & $48.8 \%$ \\
\hline 5 & $0.633 \pm 0.197$ & $31.1 \%$ & $0.0930 \pm 0.0293$ & $31.5 \%$ & $0.1009 \pm 0.0342$ & $33.9 \%$ \\
\hline 6 & $0.630 \pm 0.174$ & $27.6 \%$ & $0.0554 \pm 0.0267$ & $48.2 \%$ & $0.0675 \pm 0.0344$ & $50.9 \%$ \\
\hline 7 & $0.516 \pm 0.210$ & $40.7 \%$ & $0.0696 \pm 0.0259$ & $37.2 \%$ & $0.0942 \pm 0.0384$ & $40.8 \%$ \\
\hline 8 & $0.388 \pm 0.105$ & $27.1 \%$ & $0.0754 \pm 0.0210$ & $27.8 \%$ & $0.0863 \pm 0.0237$ & $27.5 \%$ \\
\hline
\end{tabular}

Values are mean \pm SD. CV $=$ coefficient of variation. 
TABLE 3. Calculated Perfusion and Innervation Defect Sizes.

\begin{tabular}{|c|c|c|c|}
\hline Subject \# & $\begin{array}{c}\mathbf{1 3}^{\mathbf{N}} \text {-Ammonia } \\
(\boldsymbol{\%} \text { Hypoperfused })\end{array}$ & $\begin{array}{c}{ }^{\mathbf{1 8}} \mathbf{F}-\mathbf{4 F}-\mathbf{M H P G} \\
(\boldsymbol{\%} \text { Denervated })\end{array}$ & $\begin{array}{c}{ }^{\mathbf{1 8}} \mathbf{F}-3 \mathbf{F}-\mathbf{P H P G} \\
\text { (\% Denervated) }\end{array}$ \\
\hline 1 & $33.0 \%$ & $60.7 \%$ & $63.6 \%$ \\
\hline 2 & $48.2 \%$ & $70.7 \%$ & $66.1 \%$ \\
\hline 3 & $63.1 \%$ & $74.3 \%$ & - \\
\hline 4 & $14.6 \%$ & $58.2 \%$ & $36.5 \%$ \\
\hline 5 & $37.0 \%$ & $39.1 \%$ & $64.1 \%$ \\
\hline 6 & $37.7 \%$ & $64.4 \%$ & $40.9 \%$ \\
\hline 7 & $41.1 \%$ & $41.9 \%$ & $25.3 \%$ \\
\hline 8 & $25.0 \%$ & $25.7 \%$ & \\
\hline
\end{tabular}

Values are the percentage of LV sectors with parameter estimates < 50\% of the maximum estimate. 
TABLE 4. Calculated Retention Index Values and Estimated Innervation Defect Sizes.

\begin{tabular}{|c|c|c|c|c|c|c|}
\hline $\begin{array}{c}\text { Subject } \\
\quad \#\end{array}$ & $\begin{array}{c}{ }^{18} \mathrm{~F}-4 \mathrm{~F}-\mathrm{MHPG} \\
\mathrm{RI} \\
\text { (mL blood } / \mathrm{min} / \mathrm{mL} \\
\text { tissue) }\end{array}$ & $\begin{array}{l}\text { CV } \\
(\%)\end{array}$ & $\begin{array}{c}{ }^{18} \mathrm{~F}-3 \mathrm{~F}-\mathrm{PHPG} \\
\mathrm{RI} \\
\begin{array}{c}\mathrm{mL} \text { blood } / \mathrm{min} / \mathrm{mL} \\
\text { tissue })\end{array}\end{array}$ & $\begin{array}{l}\mathrm{CV} \\
(\%)\end{array}$ & $\begin{array}{c}{ }^{18} \mathrm{~F}-4 \mathrm{~F}-\mathrm{MHPG} \\
\text { (\% Denervated) }\end{array}$ & $\begin{array}{c}{ }^{18} \mathrm{~F}-3 \mathrm{~F}-\mathrm{PHPG} \\
\text { (\% Denervated) }\end{array}$ \\
\hline 1 & $0.0386 \pm 0.0148$ & $38.3 \%$ & $0.0576 \pm 0.0268$ & $46.5 \%$ & $57.6 \%$ & $62.2 \%$ \\
\hline 2 & $0.0363 \pm 0.0157$ & $43.3 \%$ & $0.0381 \pm 0.0174$ & $45.7 \%$ & $70.9 \%$ & $64.3 \%$ \\
\hline 3 & $0.0220 \pm 0.0133$ & $60.5 \%$ & - & - & $73.7 \%$ & - \\
\hline 4 & $0.0263 \pm 0.0118$ & $44.9 \%$ & $0.0649 \pm 0.0315$ & $48.5 \%$ & $56.7 \%$ & $63.1 \%$ \\
\hline 5 & $0.0414 \pm 0.0128$ & $30.9 \%$ & $0.1021 \pm 0.0349$ & $34.2 \%$ & $37.7 \%$ & $34.4 \%$ \\
\hline 6 & $0.0339 \pm 0.0152$ & $44.8 \%$ & $0.0498 \pm 0.0243$ & $48.8 \%$ & $63.1 \%$ & $63.1 \%$ \\
\hline 7 & $0.0433 \pm 0.0160$ & $37.0 \%$ & $0.0617 \pm 0.0245$ & $39.7 \%$ & $41.6 \%$ & $40.2 \%$ \\
\hline 8 & $0.0670 \pm 0.0188$ & $28.1 \%$ & $0.0968 \pm 0.0264$ & $27.3 \%$ & $27.6 \%$ & $24.4 \%$ \\
\hline
\end{tabular}

Values are mean \pm SD. $\mathrm{RI}=$ retention index, $\mathrm{CV}=$ coefficient of variation. 
FIGURE 1

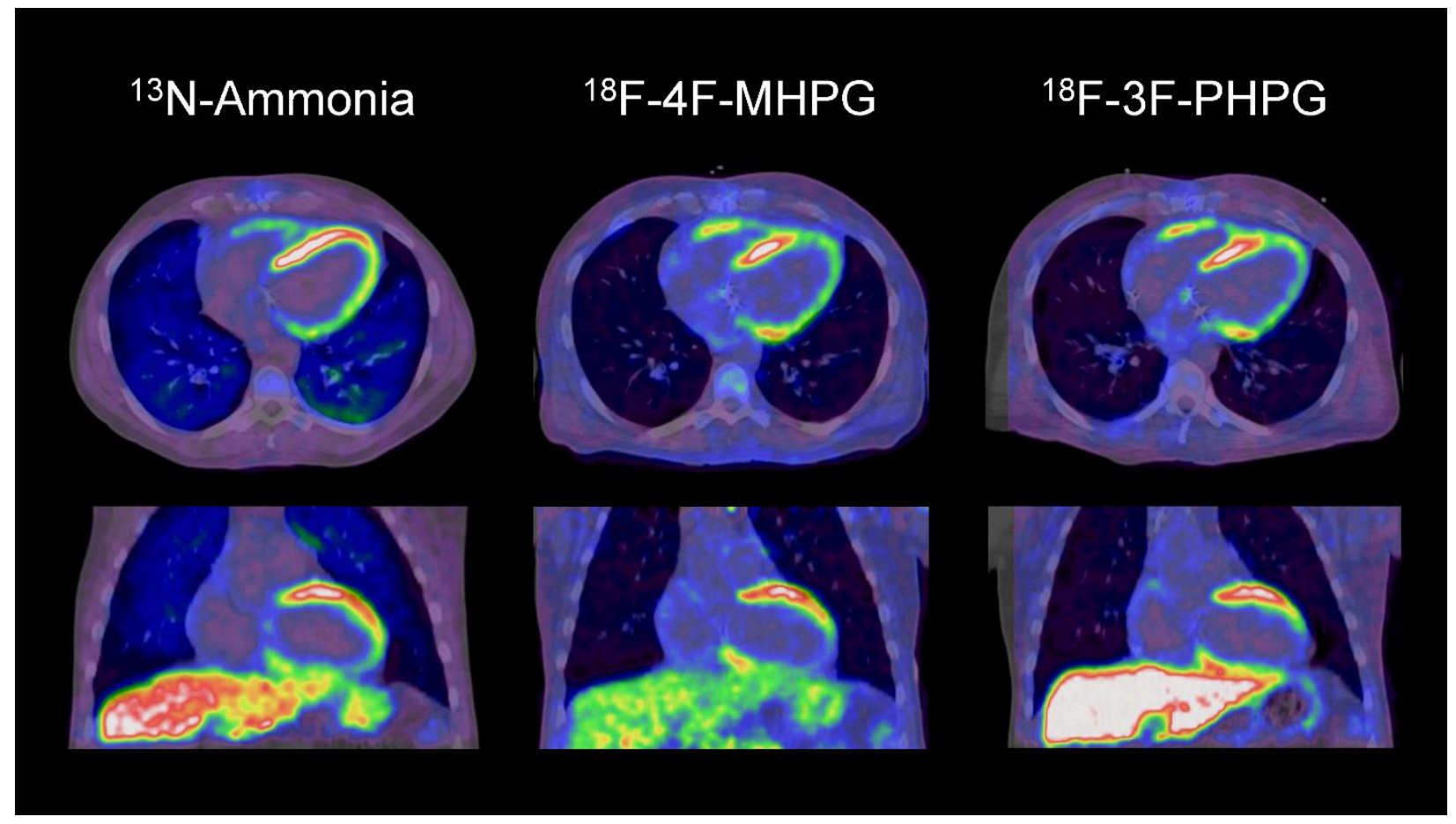


FIGURE 2
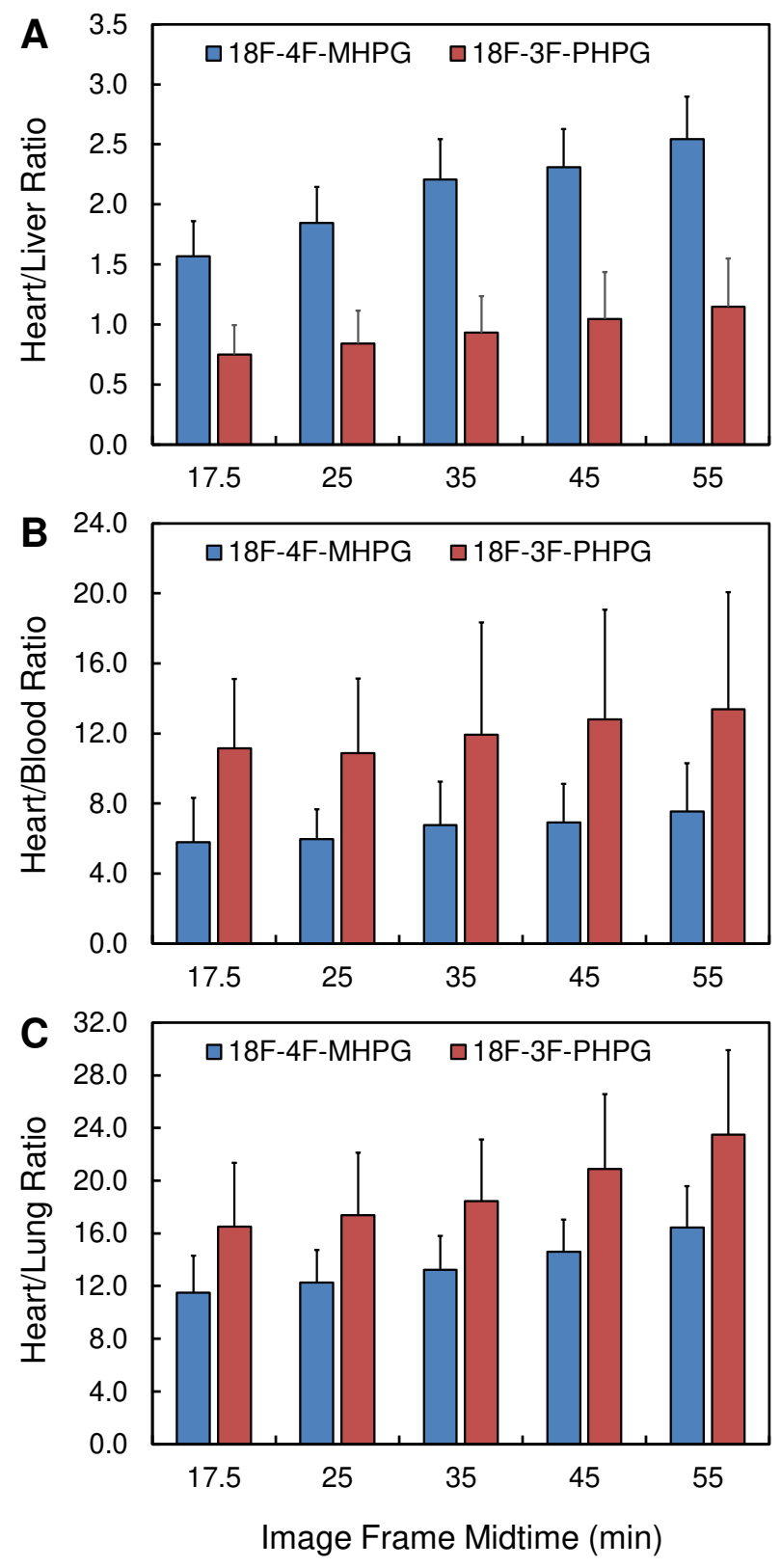


\section{FIGURE 3}

\section{${ }^{18} \mathrm{~F}-4 \mathrm{~F}-\mathrm{MHPG} \quad{ }^{18 F-3 F-P H P G}$}
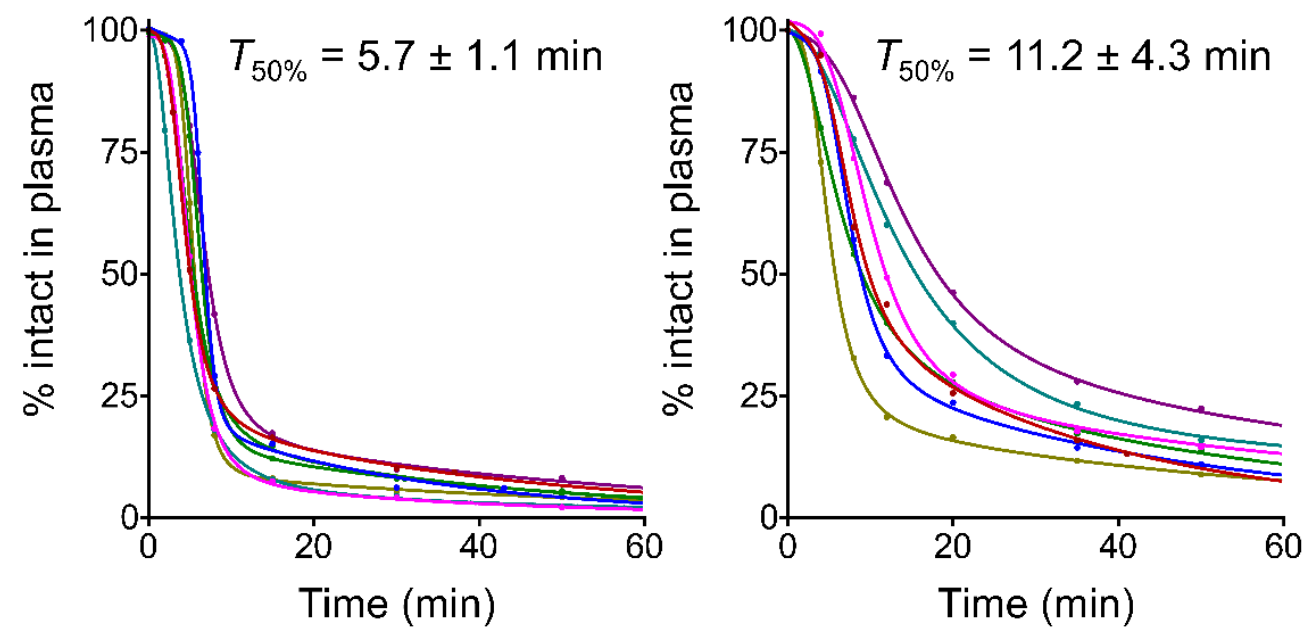


\section{FIGURE 4}
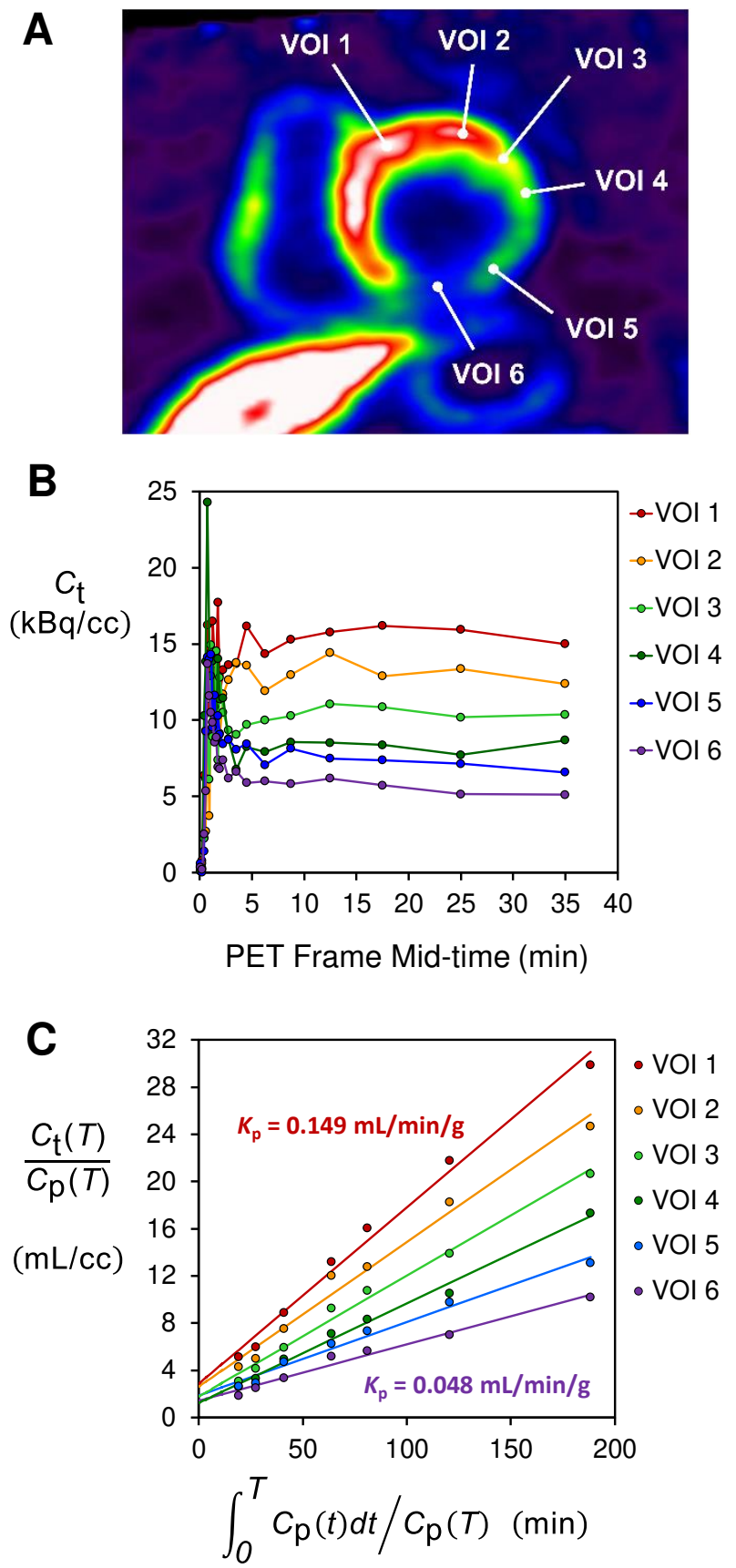


\section{FIGURE 5}
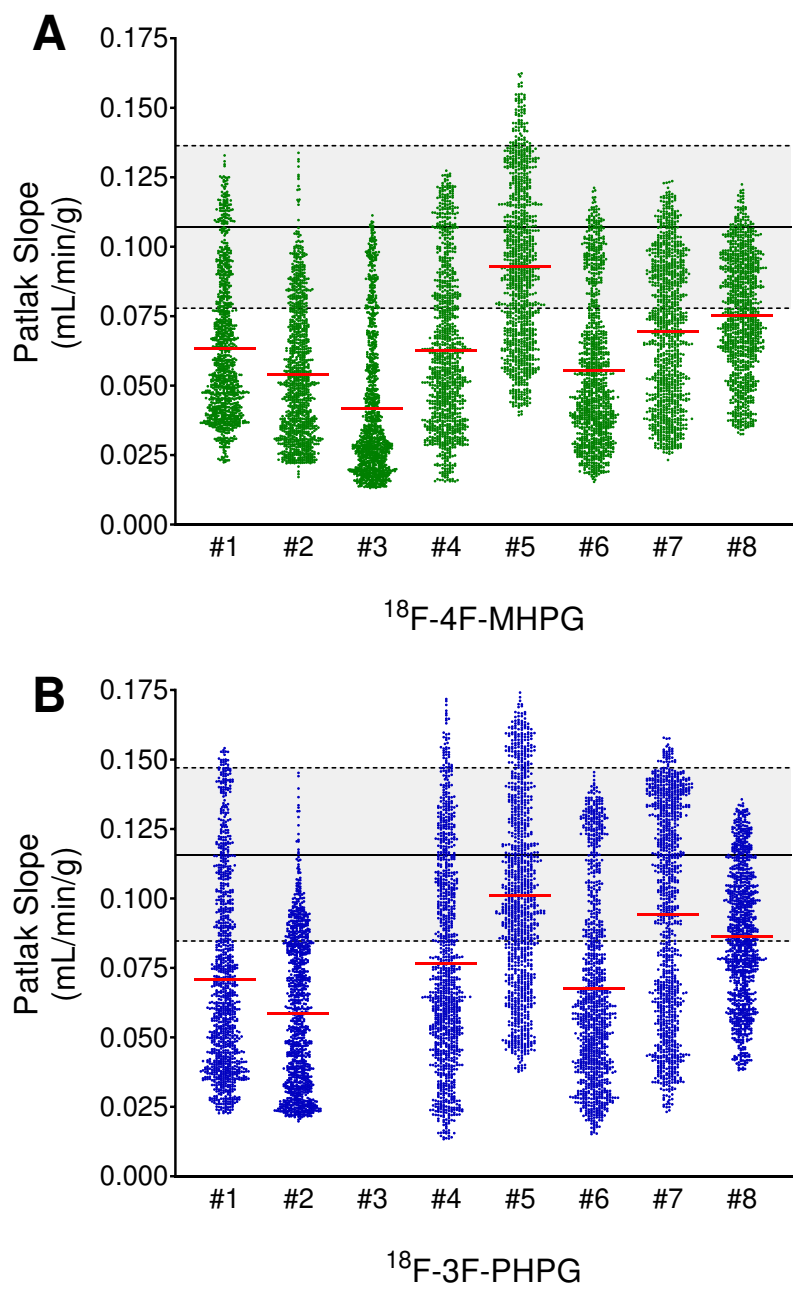


\section{FIGURE 6}

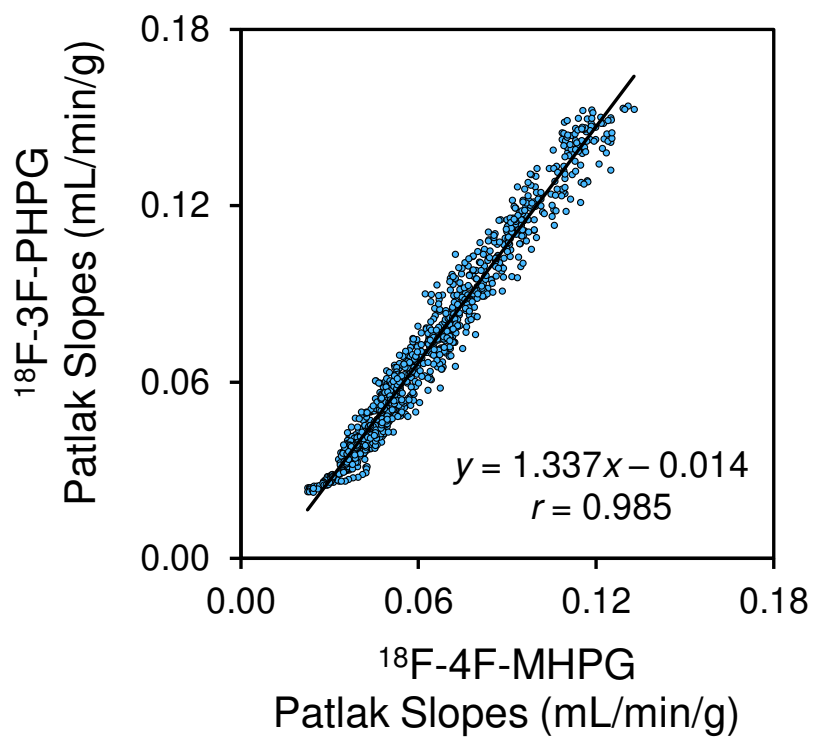


FIGURE 7
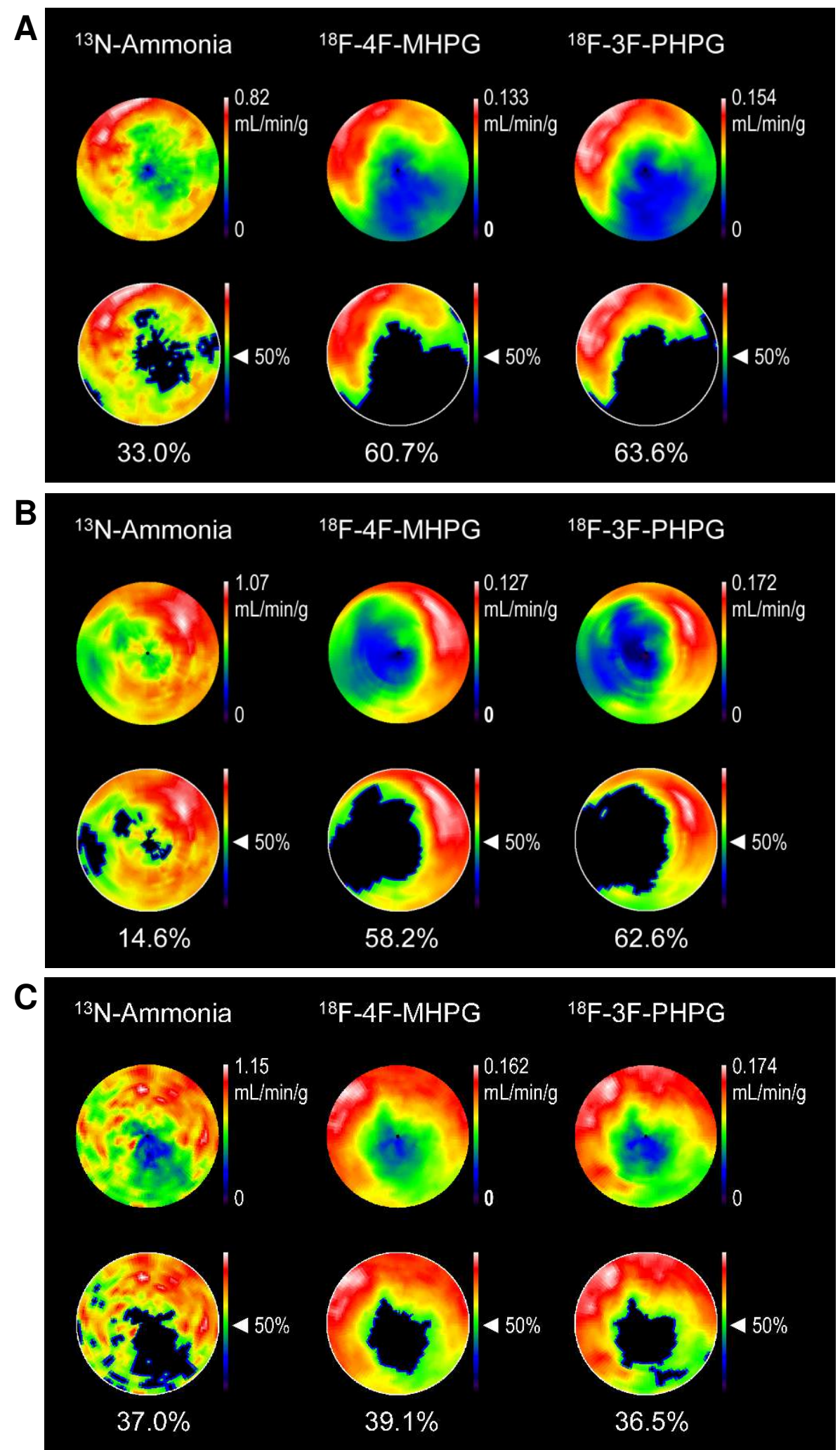


\section{FIGURE 8}
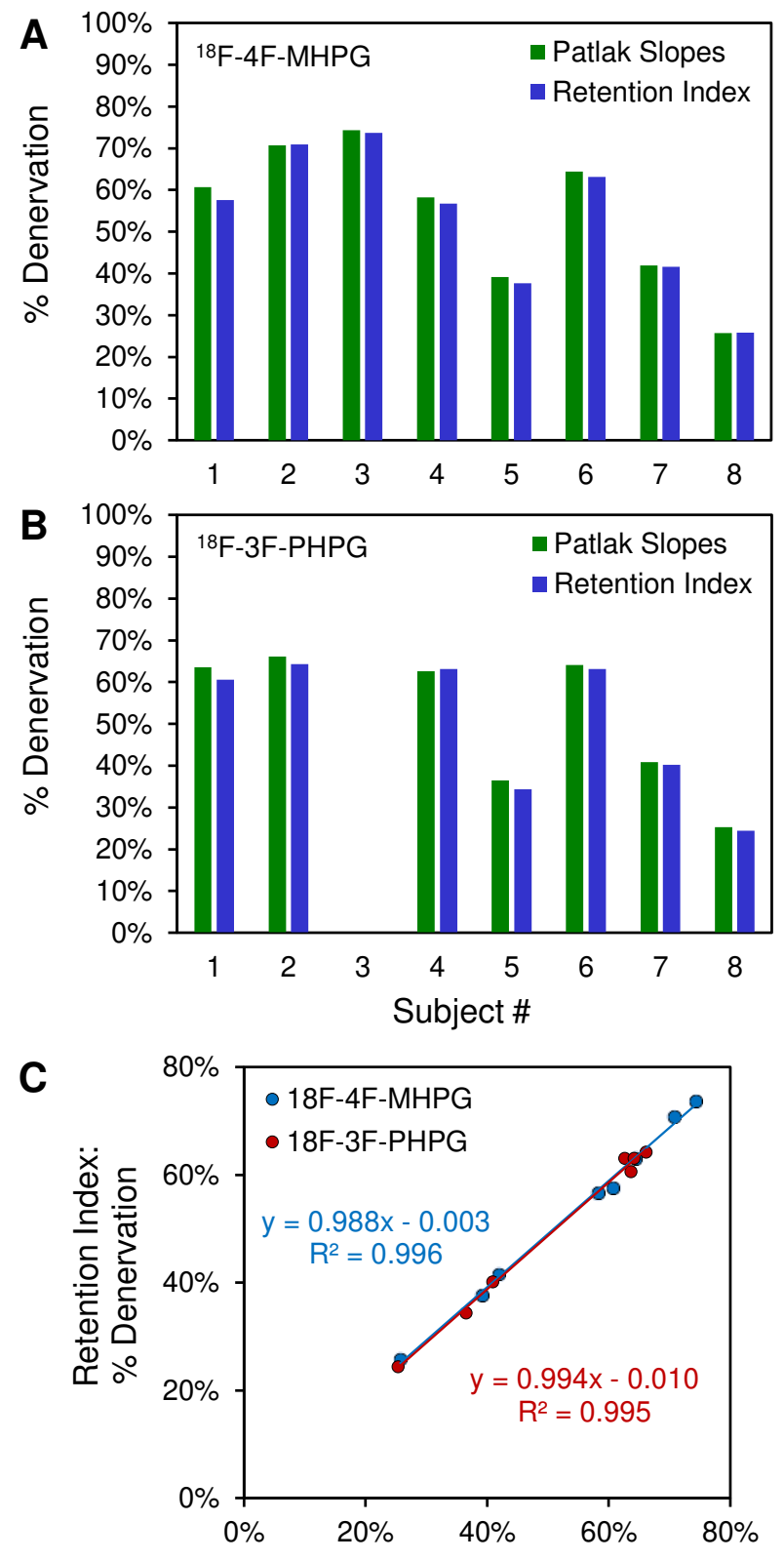

Patlak Slope: \% Denervation 
Figures

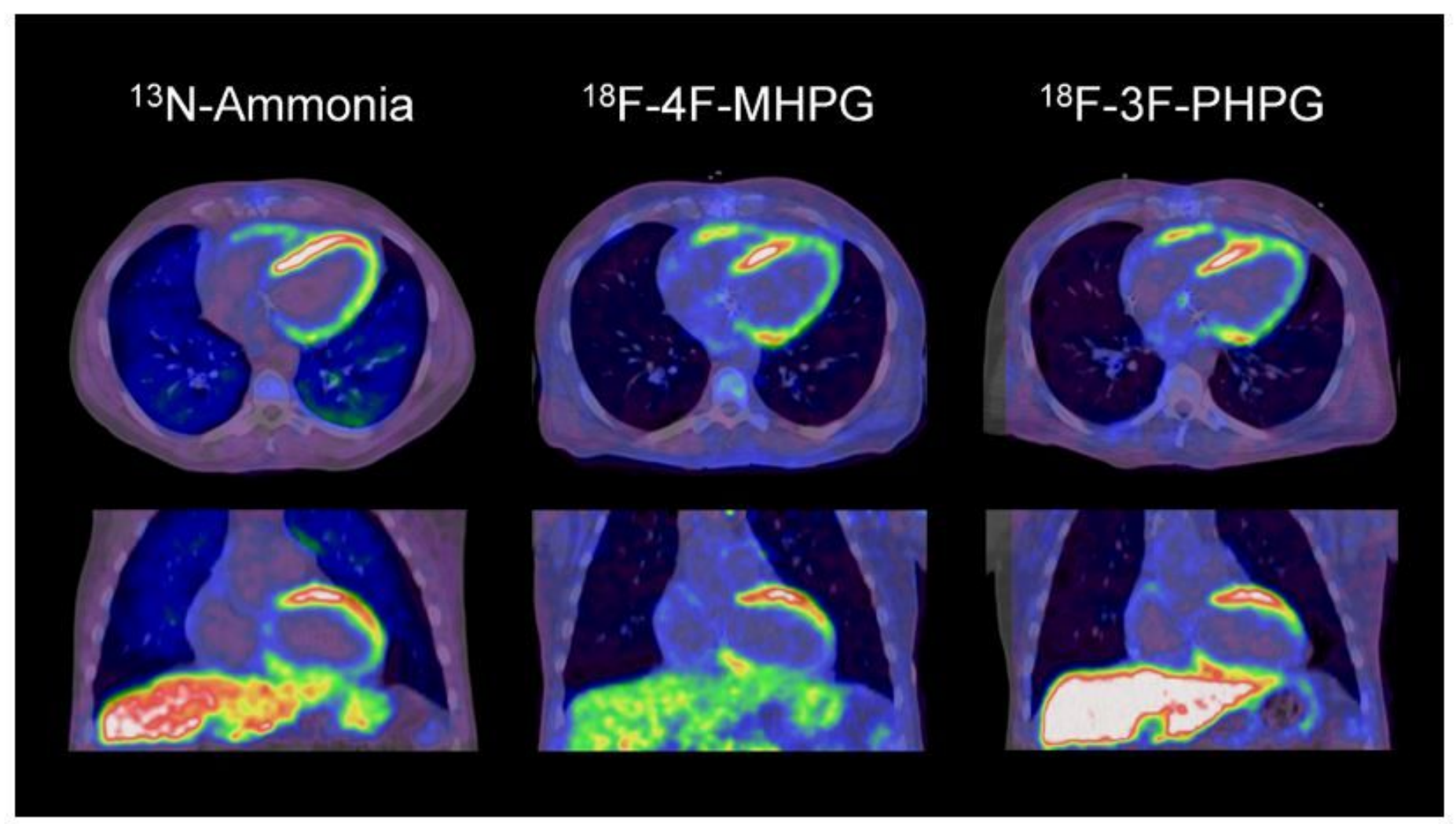

Figure 1

Representative final transaxial (top row) and coronal (bottom row) fused PET/CT images (Subject \#6) 

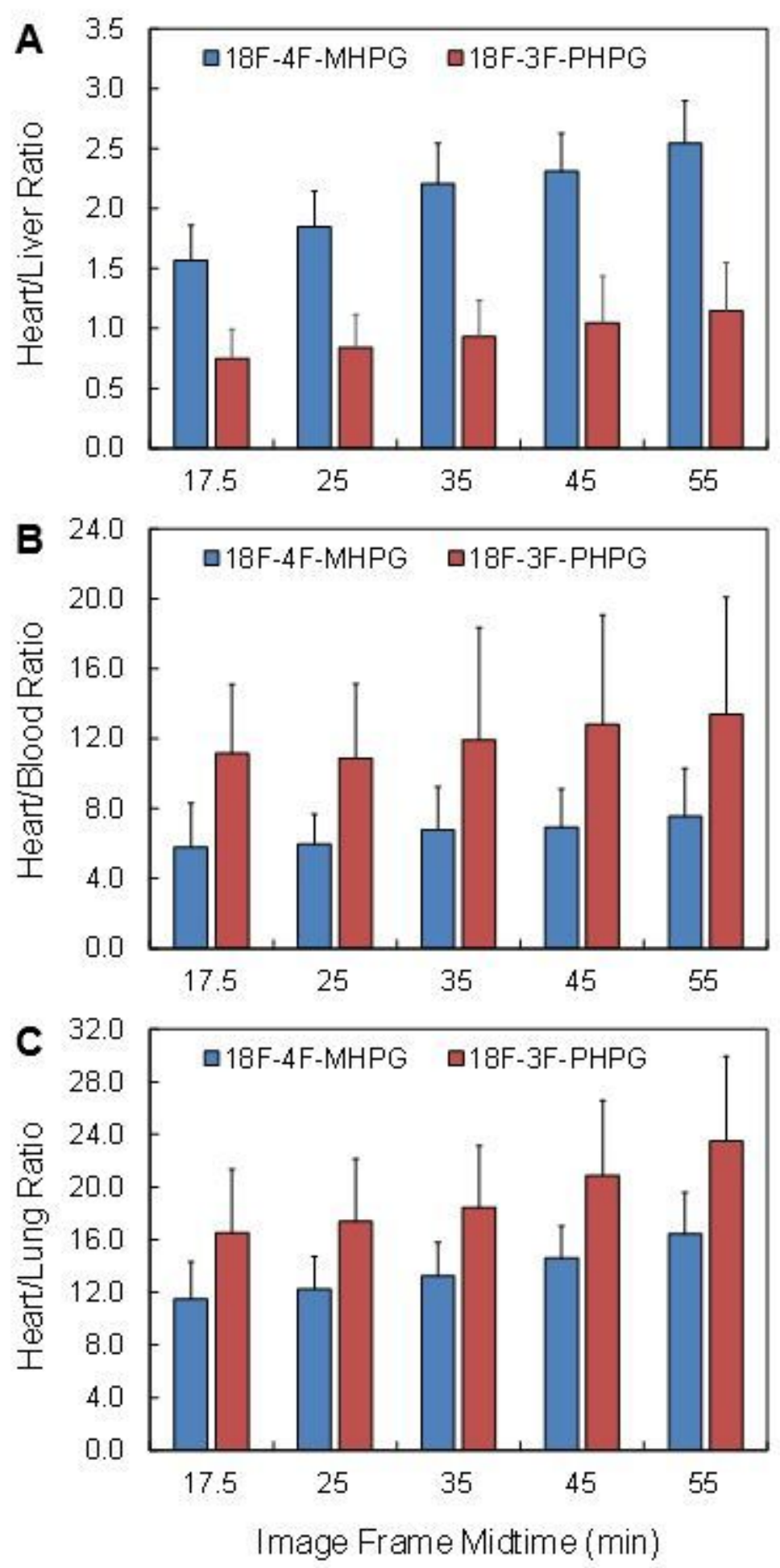

Figure 2

Mean tissue activity concentration ratios for peak heart-to-liver (A), peak heart-to-blood (B) and peak heart-to-lung (C) in the last five PET image frames. 
${ }^{18} \mathrm{~F}-4 \mathrm{~F}-\mathrm{MHPG}$

${ }^{18} \mathrm{~F}-3 \mathrm{~F}-\mathrm{PHPG}$
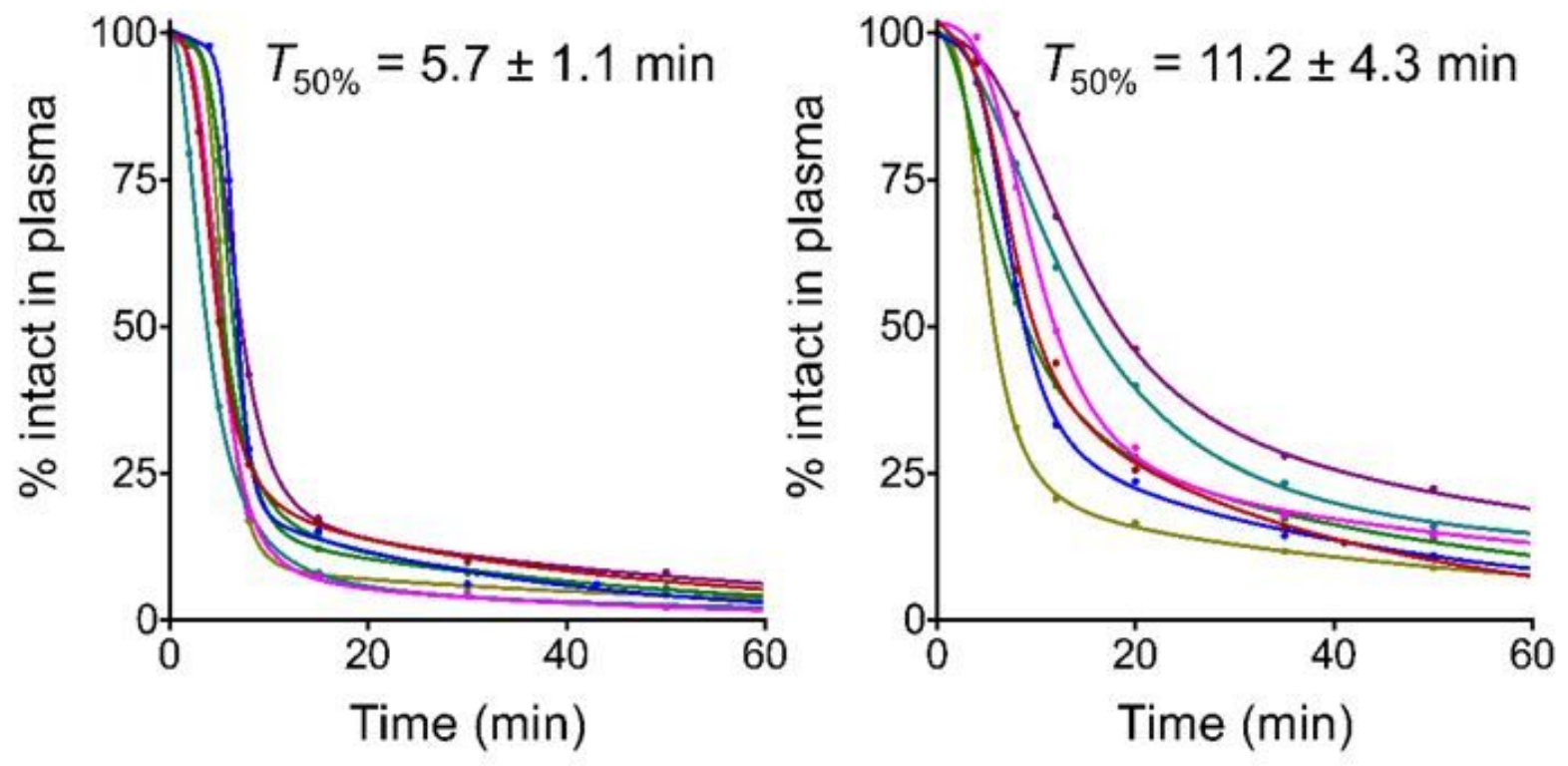

Figure 3

Metabolism of 18F-4F-MHPG (left) and 18F-3F-PHPG (right) in plasma. Mean times at which $50 \%$ of plasma activity remains as intact radiotracer $(T 50 \%)$ are shown (mean \pm SD) 

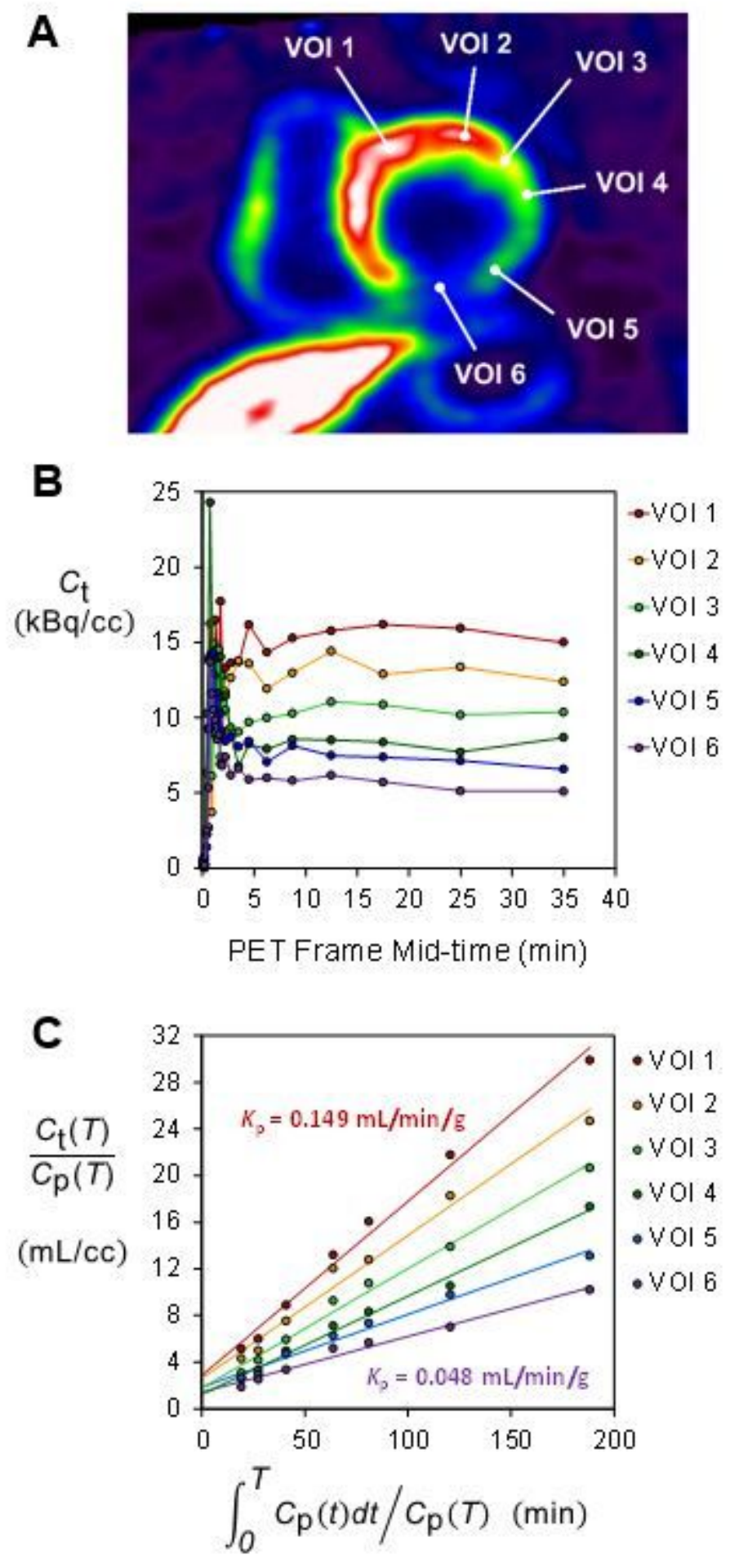

Figure 4

(A) 18F-3F-PHPG image for Subject \#1 showing VOI locations of representative kinetic data. (B) 18F-3FPHPG kinetics in regions with different sympathetic nerve densities, from normal (red) down to severe denervation (violet). (C) Corresponding Patlak plots for the kinetic data shown in (B), demonstrating the decline of the Patlak slope with decreasing nerve density. VOI = volume-of-interest 

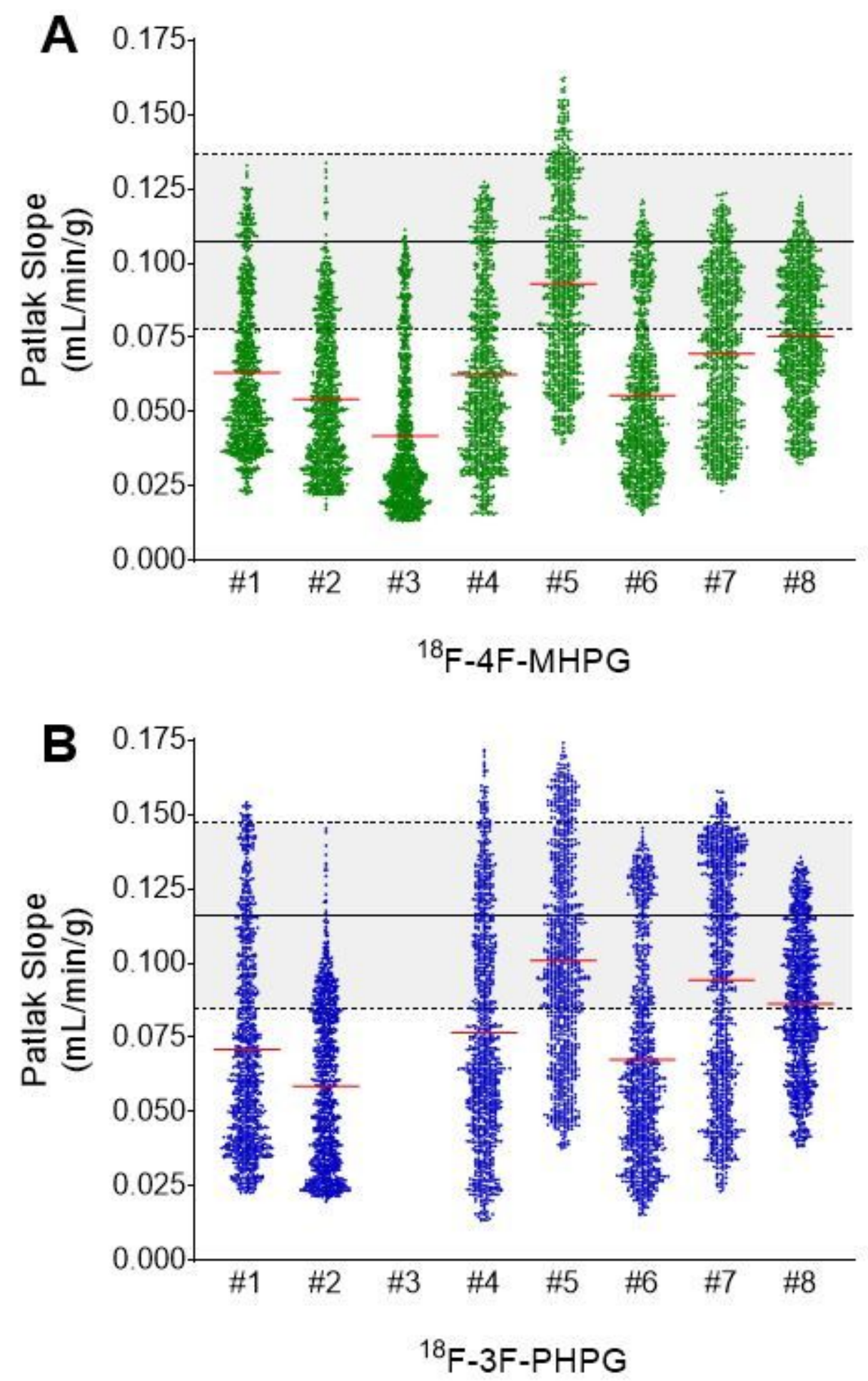

Figure 5

Distribution of regional Patlak slopes in each subject for (A) 18F-4F-MHPG and (B) 18F-3F-PHPG. The normal range of Patlak slopes is illustrated by a black line representing the mean Patlak slopes measured previously in healthy control subjects and a gray shaded area representing $\pm 2 \times$ SD around the normal mean. Red lines represent the mean Patlak slope for each subject 


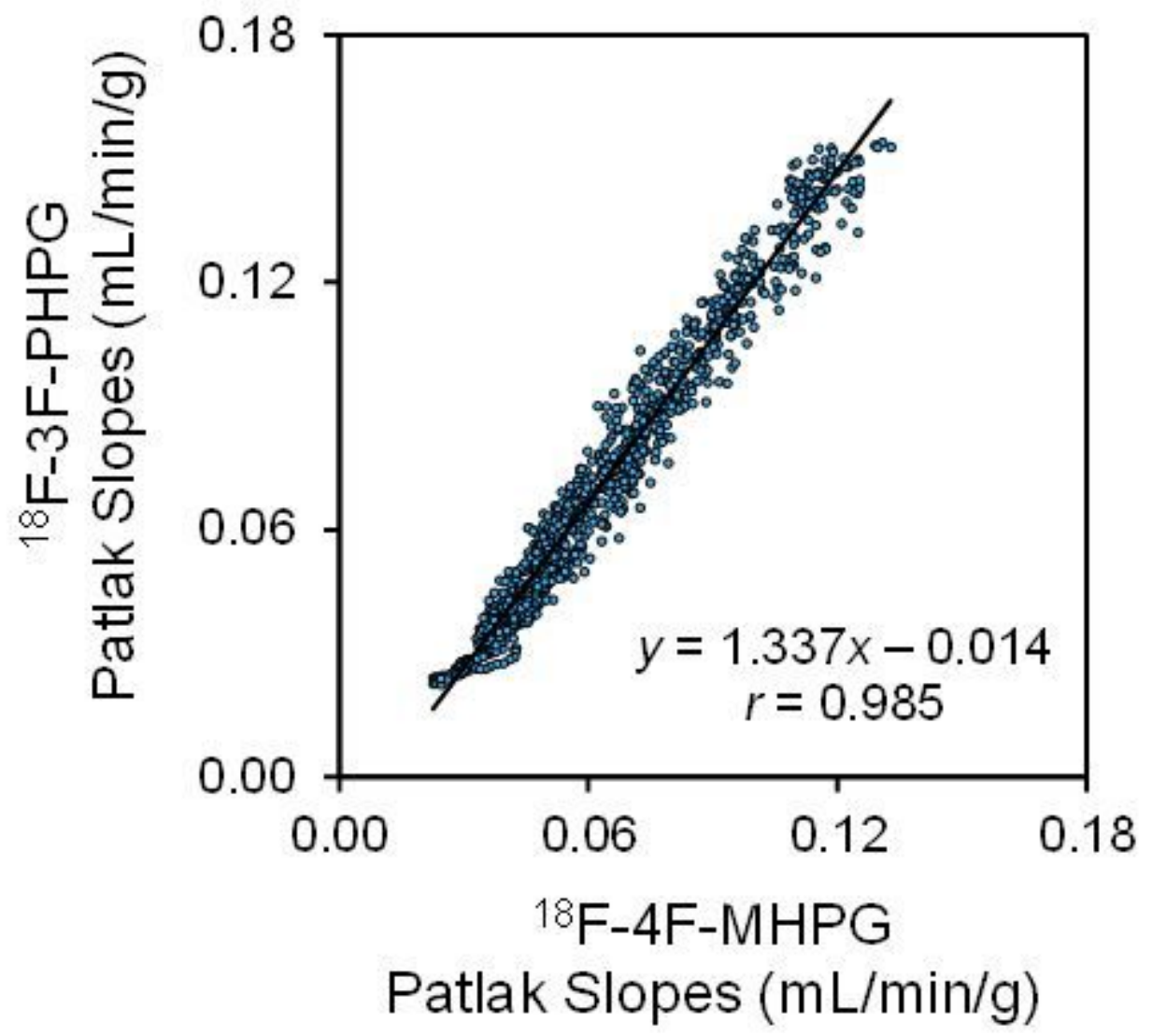

Figure 6

Plot of regional Patlak slopes measured with 18F-3F-PHPG versus 18F-4F-MHPG in Subject \#1, showing a high linear correlation $(r=0.985) . r=$ linear correlation coefficient 


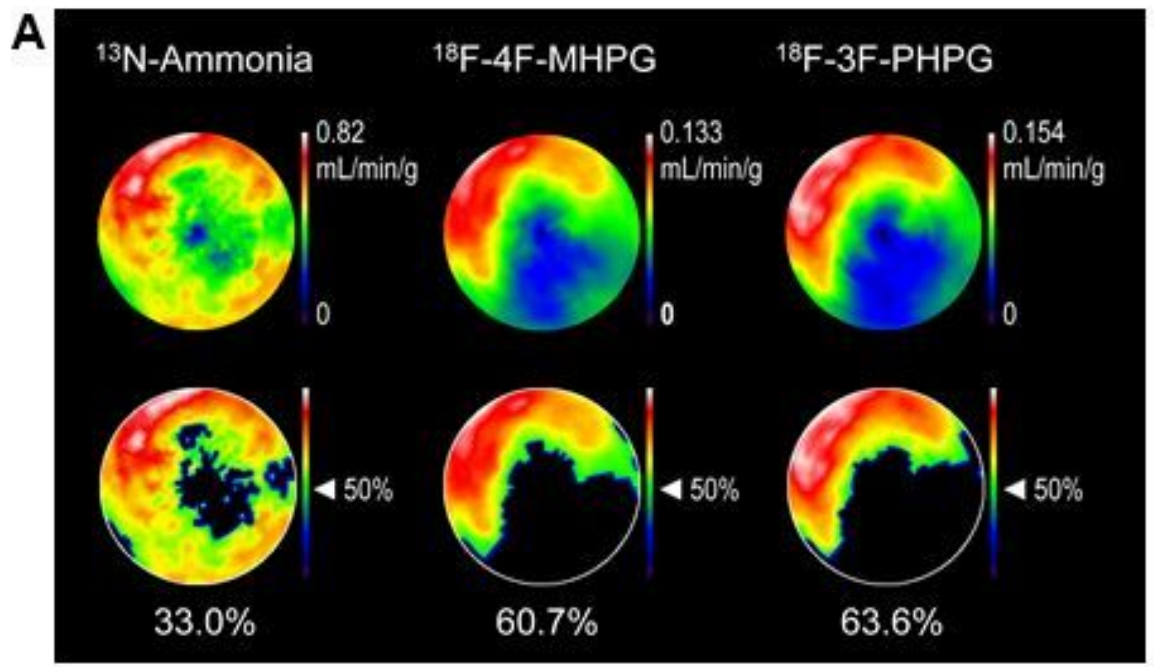

B

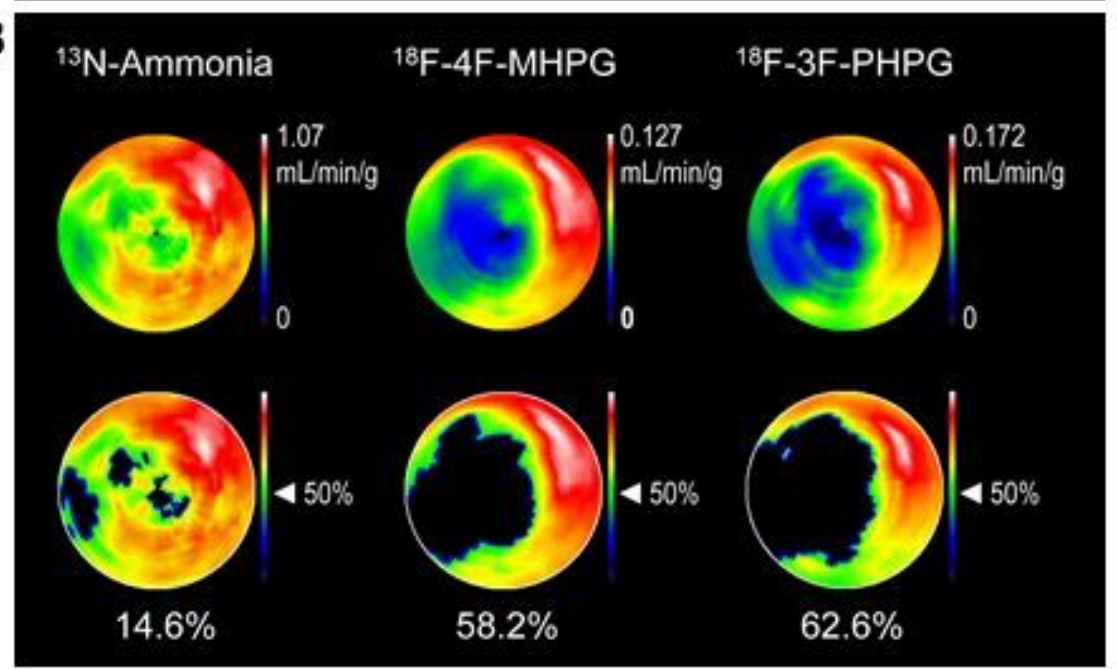

c

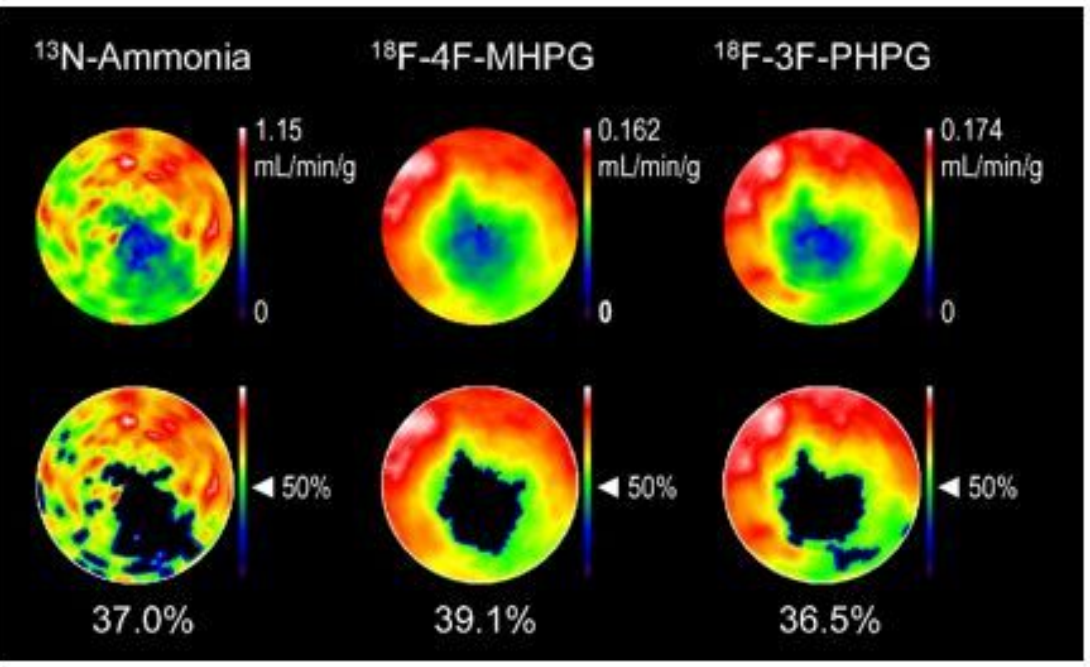

\section{Figure 7}

Representative polar maps of resting perfusion measured with $13 \mathrm{~N}$-ammonia and Patlak slopes as metrics of regional sympathetic nerve density measured with 18F-4F-MHPG and 18F-3F-PHPG (top row). Corresponding maps with areas of hypoperfusion or denervation blacked out are shown below (bottom row) along with quantitative estimates of the extents of hypoperfusion or denervation. A: Subject \#1, age $74 \mathrm{y}, \mathrm{BMI}=46, \mathrm{NYHA}$ class III, LVEF = 18\%, with ischemic cardiomyopathy. $\mathrm{B}$ : Subject \#4, age $67 \mathrm{y}, \mathrm{BMI}=$ 
23, NYHA Class I, LVEF $=35 \%$ with an anteroseptal myocardial infarction five months earlier. C: Subject $\# 5$, age $37 \mathrm{y}, \mathrm{BMI}=27, \mathrm{NYHA}$ class I, LVEF $=22 \%$, with nonischemic cardiomyopathy. $\mathrm{BMI}=$ body mass index, NYHA = New York Heart Association, LVEF = left ventricular ejection fraction
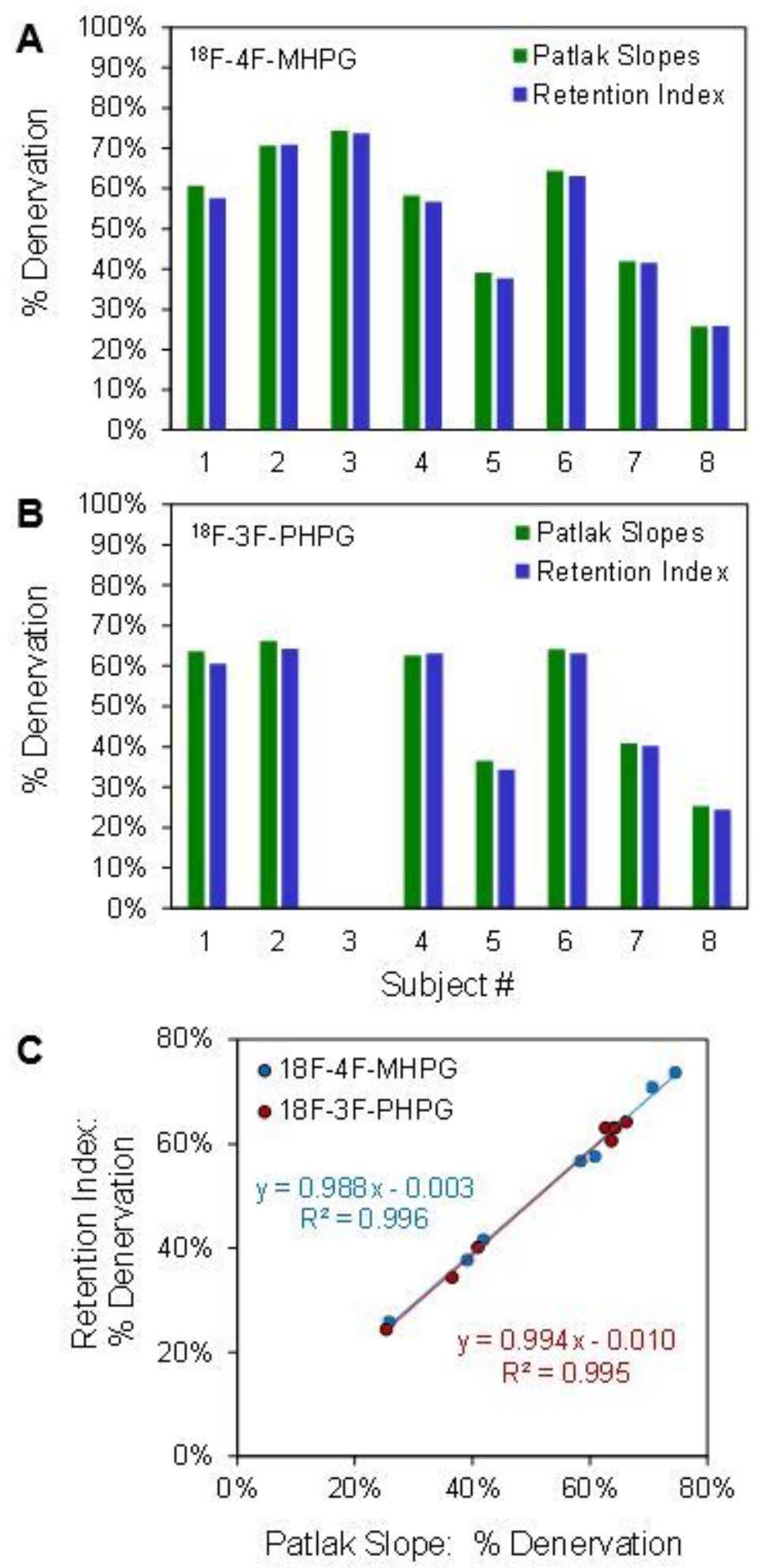

Figure 8

Comparison of extent of denervation metrics calculated using Patlak slopes and RI values for $18 \mathrm{~F}-4 \mathrm{~F}-$ MHPG (A) and 18F-3F-PHPG (B). Denervation extent measures obtained using RI values were linearly 
correlated with those obtained using Patlak slopes (C) 